\title{
Monetary Policy and Stock Market Booms
}

\author{
Lawrence Christiano*, Cosmin llut**, Roberto Motto*** and \\ Massimo Rostagno*** \\ * Northwestern University and National Bureau of Economic Research \\ ** Duke University \\ *** European Central Bank
}

\author{
DT. N²011-005 \\ Serie de Documentos de Trabajo \\ Working Paper series \\ Marzo 2011
}

Los puntos de vista expresados en este documento de trabajo corresponden a los autores y no reflejan necesariamente la posición del Banco Central de Reserva del Perú.

The views expressed in this paper are those of the authors and do not reflect necessarily the position of the Central Reserve Bank of Peru. 


\title{
Monetary Policy and Stock Market Booms*
}

\author{
Lawrence Christiano ${ }^{\dagger}$ Cosmin Ilut
}

September 24, 2010

\begin{abstract}
Historical data and model simulations support the following conclusion. Inflation is low during stock market booms, so that an interest rate rule that is too narrowly focused on inflation destabilizes asset markets and the broader economy. Adjustments to the interest rate rule can remove this source of welfare-reducing instability. For example, allowing an independent role for credit growth (beyond its role in constructing the inflation forecast) would reduce the volatility of output and asset prices.

JEL numbers: E42, E58

Key words: inflation targeting, sticky prices, sticky wages, stock price boom, DSGE model, New Keynesian model, news, interest rate rule.

\footnotetext{
*Prepared for Macroeconomic Challenges: the Decade Ahead, A Symposium Sponsored by the Federal Reserve Bank of Kansas City Jackson Hole, Wyoming August 26 - 28, 2010. The views expressed in this paper are those of the authors and do not necessarily reflect those of the ECB or the Eurosystem. We are grateful for discussions with David Altig, Gadi Barlevy, Martin Eichenbaum, Ippei Fujiwara and Jean-Marc Natal, and for comments from John Geanakoplos. We have also benefited from the advice and assistance of Daisuke Ikeda and Patrick Higgins.

${ }^{\dagger}$ Northwestern University and National Bureau of Economic Research.

$\ddagger$ Duke University.

$\S$ European Central Bank.

『European Central Bank.
} 


\section{Introduction and Summary}

The interaction between monetary policy and asset price volatility has been a matter of increased concern since the collapse of stock market booms in 2000 and 2007. Are booms like these suboptimal? Is monetary policy partially responsible for stock market booms? Should monetary policy actively seek to stabilize stock market booms? These classic questions have been put back on the table by the experience of the past two decades.

\subsection{The conventional wisdom}

There is, we believe, a conventional wisdom on the answers to these questions. Booms arise for reasons largely unrelated to the conduct of monetary policy. Some booms are indeed excessive. But, it is unwise to identify which booms are excessive and to actively resist them using interest rate policy. The conventional wisdom is that, in any case, a strategy of raising the policy interest rate when the inflation forecast is high and reducing it when the inflation forecast is low should help to dampen excessive volatility. The notion is that booms which are excessive involve a rise in stock prices above levels justified by fundamentals. Such a boom represents a surge in demand because there is nothing currently on the supply side of the economy to justify it. In a demand boom, however, one expects inflation to be high. The policy of inflation forecast targeting using an interest rate rule 'leans against the boom' at precisely the right time. This conventional wisdom was given an intellectually coherent foundation in two very influential papers (Bernanke and Gertler $(1999,2001)$ ).

\subsection{Data}

We explore an alternative perspective on the relationship between monetary policy and booms. We are motivated to consider this alternative by the historical record of United States (US) stock market booms as well as by the Japanese stock market boom of the 1980s. We find that inflation was relatively low in each of the 18 US stock market boom episodes that occurred in the past two centuries. ${ }^{1}$ The Japanese case is particularly striking, with inflation slowing sharply during the boom from its pre-boom level. The notion that stock market booms are not periods of high inflation, and that they are if anything periods of low inflation is not new to this paper. The recent work of Adalid and Detken (2007), Bordo and Wheelock $(2004,2007)$ and White (2009) also draws attention to this observation. Here, we stress the implications for monetary policy. The historical record suggests that, at least at an informal level, a monetary policy which implements inflation forecast targeting using an interest rate rule would actually destabilize asset markets. The lower-than-average inflation of the boom would induce a fall in the interest rate and thus amplify the rise in stock prices in the boom.

A noticeable feature of stock market booms is that, with the exception of only 2 of the 18 booms in our US data set, credit growth is always stronger during a boom than outside a boom. On average, credit growth is twice as high in booms than it is in non-boom periods. Casual reasoning suggests that volatility would be reduced if credit growth were tightened as booms get underway. In practice, this tightening in response to credit growth would not

\footnotetext{
${ }^{1}$ We exclude the Civil War and WWI and II from our dataset.
} 
be justifiable based on the inflation outlook alone because booms are not in fact periods of elevated inflation. The idea that credit growth should be assigned an independent role in monetary policy has been advocated in several papers. We have advocated this position in work that we build on here (Christiano, Ilut, Motto and Rostagno (2008)). ${ }^{2}$

According to the conventional wisdom, it is only the 'excessive' booms that are inflationary. Assuming at least some of the booms considered in this paper are excessive, our results contradict the conventional wisdom that inflation accelerates during such booms. Indeed, the results raise the possibility that monetary policy is in part responsible for at least some booms, by responding to the fall in inflation with interest rate cuts.

\subsection{Interpreting the data with a New Keynesian model}

Our empirical results raise an important question. How could it be that a stock market boom based purely on expectations about the future, which is therefore driven purely by demand, not raise inflation? At first glance, the apparent finding that inflation is low during such booms may appear simply odd. Without a coherent framework to make sense out of it, one is reluctant to make an apparent anomaly the foundation for constructing a monetary policy strategy. This is why we turn to model simulations.

We show that the standard New Keynesian model provides an intellectual foundation for the notion that inflation is relatively weak in a boom. This is so, even in a boom that is only based on optimistic (possibly ill-founded) expectations about the future, and not on real current developments. Our simulations provide support for the notion that a monetary policy which focuses heavily on inflation can exacerbate booms. No doubt there exist improvements to banking supervision and credit market regulations that can moderate asset price volatility. ${ }^{3}$ However, it seems inefficient to use supervision and regulation to remove volatility injected by monetary policy. That source of volatility could instead be removed by an adjustment to monetary policy.

We begin with the simplest possible New Keynesian model, the one analyzed in Clarida, Gali and Gertler (1999) and Woodford (2003). Because this model does not have capital in it, we cannot use it to think about a stock market boom. Still, we can use the model to think about booms driven only by optimism about the future, why inflation might be low at such a time, and how an inflation forecast targeting interest rate rule might be destabilizing under these circumstances. ${ }^{4}$ This analysis gets at the core of the issue - how inflation could be low in a demand-driven boom - and creates the basic intuitive foundation for understanding the later results based on models that do incorporate asset prices.

\footnotetext{
${ }^{2}$ See also Christiano, Motto and Rostagno (2007). The position is often labelled 'the BIS view' (see, Eichengreen (2009), White (2009) and the references therein). For an application of the Christiano, Ilut, Motto and Rostagno (2008) analysis to the Japanese economy, see Christiano and Fujiwara (2006). In related work, Cecchetti, Genberg, Lipsky and Wadhwani (2000) argue that monetary policy should also react to movements in the stock market.

${ }^{3}$ We are sympathetic to the idea (see, for example, Hirtle, Schuermann, and Stiroh (2009)) that a macroprudential perspective ought to be brought to bear on the supervision and regulation of financial firms. See, for example, Barlevy (2008), Evans (2010) and Geanakoplos (2009).

${ }^{4}$ In developing the intuition for our model results, we stress the case where the interest rate rule is a function of expected future inflation. However, we show that the results are robust to the assumption that the interest rate rule is a function of current, actual inflation.
} 
We assume that people receive a signal which leads them to expect that a cost-saving technology will become available in the future. In the model, prices are set as a function of current marginal costs as well as future marginal costs. The expectation that marginal costs in the future will be lower dampens the current rise in prices. The inflation forecast targeting interest rate rule leads the monetary authority to cut the interest rate, stimulating the demand for goods. Output expands to meet the additional demand, raising current marginal costs. The expected future reduction in marginal cost exceeds the current rise, so that prices actually fall during the boom. ${ }^{5}$

That prices are set in part as a function of future marginal costs is essential to our analysis. In the model, forward looking price setting reflects the presence of price adjustment frictions. However, it is easy to think of other reasons why price setters might be forward looking. For example, firms may be motivated to seek greater market share in order to be in a better position in the future to profit from anticipated new future technologies. The drive for greater market share may lead to a pattern of price cutting. This particular strategy for responding to anticipations of improved technology is one that has, for example, been stressed by Jeff Bezos, the CEO of Amazon. ${ }^{6}$

\subsection{Why an inflation forecast targeting interest rate rule may destabilize a boom}

The boom that occurs in the wake of a signal about future technology in our model simulation is excessive in a social welfare sense. Its magnitude reflects the suboptimality of the inflation forecast targeting interest rate rule. The monetary policy that maximizes social welfare responds to the optimistic expectations by raising the real interest rate sharply (we refer to the socially optimal interest rate as 'the natural rate of interest'). The reason for the sharp rise in the natural rate of interest is simple. The expectation of higher future consumption opportunities creates the temptation to increase consumption right away. But, such an increase is inefficient because the basis for it - improved technology - is not yet in place. In a world where markets operate smoothly the efficient outcome - a delay in the urge to consume is automatically brought about by a rise in the real interest rate. In such a world, the natural and actual rates of interest coincide. In the world of our model, the smooth operation of markets is hampered by price and wage frictions and the monetary authority's control over the nominal rate of interest gives it control over the real interest rate. This control can be used for good or ill: the monetary authority has the power to make the real rate of interest close to or far from the natural rate of interest. The monetary authority using an inflation forecast targeting interest rate rule responds to the signal about future productivity in exactly the wrong way. The monetary authority observes downward pressure on inflation in the wake of the signal, and responds by reducing the interest rate. The difference between the high interest rate that is optimal and the low interest rate that actually occurs represents a substantial and socially suboptimal monetary stimulus. The boom that occurs in the wake of a signal of improved future technology is largely a phenomenon of loose monetary policy,

\footnotetext{
${ }^{5}$ Barsky and Sims (2010) provide vector autoregression evidence using postwar US data which suggests that a news shock much like the one considered here drives stock prices and economic activity up, and inflation down. We view this as support for our news-shock interpretation of a stock market booms.

${ }^{6}$ For example, according to one biography, "...from the beginning, Bezos sought to increase market share as quickly as possible, at the expense of profits" (see http://www.achievement.org/autodoc/page/bez0bio-1).
} 
in our model.

One way to characterize the problem with the inflation forecast targeting interest rate rule is that the rule does not assign any weight to the natural rate of interest or to any variable that is well correlated with it. Traditionally, the absence of the natural rate of interest from interest rate rules is motivated on two grounds. First, in practice this variable is hard to measure because it depends on hard-to-determine details about the structure of the economy. Second, in much of the model analysis that appears in the existing literature, the natural rate of interest fluctuates relatively little and so approximating it by a constant does not represent a very severe mistake. Regarding the first consideration, we argue that credit growth may be a good proxy for the natural rate.

Consider the second motivation for ignoring the natural rate of interest in an interest rate rule. Until recently, builders of models have assumed that shocks to the demographic factors which influence labor supply, to government spending and to the technology for producing goods and services occur without advance warning. We confirm that the natural rate of interest fluctuates relatively little in response to shocks that occur without warning. However, recently there has been increased attention to the possibility that people receive advance signals about shocks. ${ }^{7}$ Consider the case of shocks to government spending and to technology. The major government spending shocks are associated with wars. When that kind spending jumps - the troops are on the move and the bullets are flying - it does so after a lengthy period of increased tensions and political maneuvering. These events prior to actual increases in war spending represent the early signals about government spending. ${ }^{8}$ Disturbances in technology work in the same way. Signals that the information technology revolution would transform virtually everything about how business is done existed decades ago. ${ }^{9}$ We show below that the natural rate of interest fluctuates a lot more in response to a signal about a future shock than it does to a shock that occurs without any advance warning. ${ }^{10}$ That is, when we take seriously that many disturbances occur with advance warning, the assumption of a constant natural rate of interest in an interest rate rule is no longer tenable.

So, the problem with the inflation forecast interest rate targeting rule is that it reduces the interest rate in a boom triggered by optimistic expectations, while the efficient monetary policy would increase the interest rate. ${ }^{11}$ Paradoxically, we first develop this finding below

\footnotetext{
${ }^{7}$ Recent work has been stimulated by the papers of Beaudry and Portier $(2004,2006)$.

${ }^{8}$ Valerie Ramey (2009, forthcoming) has done important recent work fleshing out the idea that government spending shocks are heralded by early signals.

${ }^{9}$ See Michelle Alexopoulos (2007) for a discussion of how the publishing industry broadcasts signals about future technology changes.

${ }^{10}$ The intuition for this finding is simple. The natural rate of interest corresponds roughly to the expected growth rate of consumption from the present to the future. In New Keynesian models fit to the data, one estimates that shocks are highly persistent. For example, an unexpected jump in technology today creates the expectation of a roughly equal jump in technology in the future. The absence of substantial internal persistence in models then implies a similar pattern for consumption. This means that the expected growth rate of consumption - and, hence, the natural rate - is relatively insensitive to the shocks incorporated in standard econometric analyses. But note how very different a shock to expectations about the future is. Nothing happens in the present. Something only happens in the future. Such a shock has the potential to have a big impact on the intertemporal slope of consumption.

${ }^{11}$ Here, we are implicitly assuming that price frictions play a more important role than wage frictions. If there were only wage frictions, then optimal monetary policy would simply not reduce the interest rate. We
} 
in a model with only price frictions, in which the optimal monetary policy (i.e., the policy that sets the interest rate equal to the natural rate) completely stabilizes inflation. That is, our analysis does not necessarily challenge the wisdom of inflation targeting per se, only the effectiveness of doing so with an inflation forecast interest rate targeting rule that is principally driven by the inflation forecast. ${ }^{12}$

\subsection{Why adding credit growth to the interest rate rule may help}

Up to this point, the analysis has focused on models that are sufficiently simple that they can be analyzed with pen and paper. We then verify the robustness of the analysis by redoing it in a medium-sized New Keynesian DSGE model that incorporates capital and various frictions necessary for it to fit business cycle data well. In this model, optimism about the future triggers a fall in inflation and a rise in output, the stock market, consumption, investment and employment. The boom is primarily an artifact of the empirically estimated interest rate policy rule, in which the forecast of inflation is assigned an important role. Under the optimal monetary policy the boom would involve only a modest rise in output and this would be accomplished by a sharp rise in the rate of interest.

We use the medium-sized model to investigate the possibility, suggested by the historical data record, that assigning a role - beyond its role in forecasting inflation - to credit growth may help to stabilize booms. First, however, we must modify the model to incorporate an economically interesting role for credit. We do so by introducing financial frictions along the lines suggested in the celebrated contribution by Bernanke, Gertler and Gilchrist (1999) (BGG). We obtain the same results in this model that we found in our simple model and in the model with capital. The inflation forecast interest rate targeting rule causes the economy to over-react to the optimism about the future, though inflation during the boom is low. The natural rate of interest rises sharply in the model. When we assign a separate role for credit growth in the interest rate rule, then the response of the economy is more nearly optimal. We interpret this as signifying that credit growth is a reasonable proxy for the natural rate of interest.

\subsection{Organization of the Paper}

The paper is organized as follows. The first section below describes the data. The following section describes the analysis of our simple model. Our analysis features a baseline parameterization, but also examines the robustness of the argument to perturbations. We consider, for example, interest rate rules which look at inflation forecasts as well as at current inflation. We also consider the case where price stickiness arises because of frictions in the setting of wages rather than because of frictions in price setting per se. This is an important perturbation to consider because empirical analyses typically find that it is crucial to include wage stickiness if one is to fit the data well. The next section considers the analysis of the

elaborate on these observations in the following subsection.

${ }^{12}$ Again, we implicitly assume that the key frictions are price frictions. The case for price stabilization weakens if there are significant wage frictions. With only wage frictions, it is desirable to stabilize wages, not prices (Erceg, Henderson and Levin (2000)). 
expanded model with credit and asset markets. We offer concluding remarks at the end. Technical details are relegated to an appendix.

\section{Inflation and Credit Growth in Stock Market Booms: The Evi- dence}

This section displays data on stock market boom-bust episodes. We find that in all cases, inflation is relatively low during the boom phase in these episodes. Real credit growth was relatively high in all but two episodes. We also examine data on the Japanese stock market boom in the 1980s. As in all US stock market booms, this Japanese boom is associated with a drop in inflation. Presumably, the boom was fueled in part by the accommodative Japanese monetary policy of the time, which cut short term interest rates substantially. We show that if the Bank of Japan had followed a standard interest rate rule that assigns weight to inflation and also the output gap, then its interest rate would have been cut even more sharply. The Japanese experience of the 1980s presents perhaps the most compelling empirical case for the proposition that an interest rate rule which focuses on the forecast of inflation exacerbates stock market volatility. ${ }^{13}$

We split our US dataset into two parts. The first part covers twelve episodes in the 19th and early 20th centuries and the second considers four episodes beginning with the Great Depression. We divide out dataset in this way because we have annual observations for the first part and quarterly observations for the second part. In addition, data availability considerations requires that our concepts of credit differ slightly between the two periods.

Consider the first part of our data, which are displayed in Figure 1. The stock market index is the log of Schwert's (1990) index of common stock, after deflating by the consumer price index. ${ }^{14}$ The real output measure is the logarithm of real Gross National Product. ${ }^{15}$ Our measure of real credit is the quantity of bank loans, scaled by the consumer price index. $^{16}$ We define a stock market boom-bust episode as follows. We start with twelve

\footnotetext{
${ }^{13}$ This is a theme also developed by Shirakawa (2010), Governor of the Bank of Japan.

${ }^{14}$ Schwert (1990)'s annual index of common stock prices is available for the period 1802-1999 as series Cj797 in the Millenium Online Edition of Historical Statistics of the United States. The consumer price index is series Cc1 in the same source.

${ }^{15}$ These are series Ca9 in Historical Statistics of the United States, Millennial Edition Online. We also considered the annual industrial production index constructed in Davis (2004), which spans the period 1790 to 1915. Using this variable instead of GDP has very little impact on the results. The mean logarithmic growth rate of industrial production in the non-boom, non-civil war part of the period 1802-1914 is 4.0 percent. The corresponding mean growth rate in each of our 9 stock market boom periods is $1.2,7.2,6.8$, $5.3,11.8,4.3,8.5,4.9$ and -0.2 percent, respectively. These results are very similar to those reported for GDP in Table 2.

${ }^{16}$ Our measure of credit splices together three time series. For the years, 1819-1834 we add series Cj148 (loans and discounts, state banks) and Cj189 (loans and discounts, second bank of the United States) from Historical Statistics of the United States, Millennial Edition Online. For the period 1834 to 1896 we use 'total loans of all banks', series X582 in Chapter X ('Banking'), page 1019 of Bicentennial Edition: Historical Statistics of the United States, Colonial Times to 1970, part 2 (HSUS) . For the period 1896 to 1914 , we use series X582 in the table on page 1020 in HSUS. Though the latter two series have the same name, the coverage of the first series is incomplete, by comparison with that of the second series (see page 1011 of HSUS for details). To explain how we spliced the data, let $x_{t}$ denote the first data series, $y_{t}$ the second and $z_{t}$ the third. Let $t=t_{1}$ and $t=t_{2}$ denote the (unique) date when the first two and the second two series
} 
financial panics in the 19th century and the pre-World War I portion of the 20th century. ${ }^{17}$ These are indicated by a solid circle in Figure 1 and they are listed in Table 3. Although each panic is associated with a drop in the stock market, Figure 1 indicates that in all but three cases the stock market had already begun to drop before. We define the peak associated with a particular financial panic as the year before the panic when the stock market reached a local maximum. We define the trough before the peak as the year when the stock market reached a local minimum. The period bracketed by the trough and the peak associated with a financial panic is indicated in Figure 1 by a shaded area. In addition, we block from our analysis the period of the civil war, which is indicated by its own shaded area.

We can see from Figure 1 that in virtually every stock market boom, the price level actually declined. Moreover, in no case did the price level rise more than its average in the non-boom, non-civil war periods. In addition, we see that stock market booms are typical periods of accelerated credit growth. Table 1 quantifies the findings in Figure 1. According to that table, consumer price (CPI) inflation averaged -2.5 per cent during stock market booms, substantially less than the 0.7 percent inflation that occurred on average over nonboom periods. In addition, credit grew twice as fast, on average, during a stock market boom as during other periods. Table 1 shows just how volatile the stock market was over this period. It grew at a 10 percent pace during boom periods and shrank at a 6.3 rate in non-booms. Table 2 provides a breakdown of the data across individual boom periods. The table documents the fact, evident in Figure 1, that there is little variation in the general pattern. Inflation is lower in every stock market boom than its average value outside of booms. In the case of credit, there is only one episode in which credit growth was slower in a stock market boom than its average outside of booms. That is the boom associated with the 1884 panic.

We now turn to the data for the post World War I period. ${ }^{18}$ The data are displayed in

overlap, respectively. We let $a=y_{t_{1}} / x_{t_{1}}$ and set $\tilde{x}_{t}=a x_{t}$. We let $b=z_{t_{2}} / y_{t_{2}}$ and set $\hat{x}_{t}=b \tilde{x}_{t}, \hat{y}_{t}=b y_{t}$. Our data series is then, $\left(\hat{x}_{t}, \hat{y}_{t}, z_{t}\right)$. Our measure of credit differs from the one used in Bordo and Wheelock (2004) (see http://research.stlouisfed.org/publications/review/04/11/0411dwd.xls). First, in constructing $y_{t}$, they compute the sum of series X582 (i.e, the only series we use) plus series X583 ('total investments of all banks'). We did not include series X583 because, according to page 1011 in HSUS, X583 is composed primarily of Government debt, while we seek a measure of nonfinancial business borrowing. In any case, our results are not sensitive to the inclusion of X583. We also differ from Bordo and Wheelock in that we use data from before 1834.

${ }^{17}$ We identified these as follows. Using Google in Windows Internet Explorer (32 bit or 64 bit versions), we typed 'panic of 18' and Google completed the phrase with 10 panics. To select the episodes in the pre-World War I portion of the 20th century, we performed the same Windows Explorer exercise. We used all the panics identified in this way except the panic of 1901 which was too small to show up as a drop in the stock market in our annual data set.

${ }^{18}$ Our data on the CPI and the real value of the S\&P composite price index were taken from Robert Shiller's web page. Data on pre-world war II US real, quarterly seasonally adjusted GNP were taken from the online data appendix to Bordo and Wheelock (2004). The latter data were spliced with analogous GNP data for the post world war II period taken from the Federal Reserve Bank of St. Louis' online data base. For the period after 1946, we measured credit with the flow of funds data, "credit market instruments", taken from Haver Analytics (mnemonic, AL14TCR5). For the period, 1946-1951, these data are stocks pertaining to the fourth quarter of each year. We used log-linear interpolation to estimate observations for the first, second and third quarters in the period, 1946-1951. For the period before 1945 are credit market data are observations on corporate debt, which corresponds to variable cj876, taken from Historical Statistics of the United States Millennial Edition Online. The pre-1945 data were log-linearly interpolated and spliced with 
Figure 2. We exclude the World War II period from our analysis, and this period is indicated by the shaded area. The other shaded areas indicate six stock market booms in the 20 th and early 21st century. As in the earlier data set, each boom episode is a time of non-accelerating inflation. In several cases, inflation actually slowed noticeably from the earlier period. Note too, that stock market booms are a time of a noticeable increase in the growth rate of credit. These results in Figure 2 are quantified in tables 3 and 4. According to Table 3, CPI inflation in stock market booms is half its value in other (non-World War II) times. Credit growth, as in the 19th century, is twice as rapid in boom times as in other times. According to the results in Table 4, inflation in each of the six boom episodes considered is below its average in non-boom times. With one exception, credit growth is at least twice as fast in booms as in other periods. The exception was the boom that peaked in 1937. This started in the trough of the Great Depression.

Figure 3 displays a real index of Japanese stock prices, as well as the Japanese CPI. ${ }^{19}$ The trough and peak of the 1980s boom corresponds to 1982Q3 and 1989Q4, respectively. The time of the boom is highlighted in both Figures 3 and 4 . What is notable about Figure 3 is that CPI inflation is significantly positive before the start of the 1980s stock market boom, and it then slows significantly as the boom proceeds. Inflation even falls below zero a few times in the second half of the 1980s. We ask what a monetary authority that follows a standard inflation targeting interest rate rule would have done in the 1980s. In particular, we posit the following policy rule for setting Japanese call money rate, $R_{t}$ :

$$
R_{t}=0.7 R_{t-1}+(1-0.7)\left[R+1.5\left(\pi_{t}-\pi\right)+0.5 \text { gap }_{t}\right]
$$

where $t$ denotes quarters, gap $p_{t}$ denotes the output gap and $\pi_{t}$ denotes the actual, year-overyear rate of inflation. For $R$ and $\pi$ we used the sample average of the call money rate and the inflation rate in the period immediately preceding the boom, 1979Q1-1982Q3. Also, we used the gap estimates produced by the International Monetary Fund in the process of preparing the 'World Economic Outlook' ${ }^{20}$ The results are displayed in Figure $4 .{ }^{21}$ The starred line displays the actual call money rate, while the solid line displays the values of $R_{t}$ that solve (2.1) over the period 1979Q1-1989Q4. Note that the Bank of Japan loosened policy very significantly during the boom, bringing the interest rate down on the order of 300 basis points. That action by the Bank of Japan is thought by many to have been a mistake, and to have contributed to a stock market boom that in retrospect appears to have definitely been 'excessive' (see, e.g., Shirakawa (2010)). But, note that if the Bank of Japan had implemented the policy rule, (2.1), they would have reduced the interest rate an additional 200 basis points over what they actually did do. One has to suppose that this would only have further destabilized an already volatile market. We hasten to add a caveat

the post 1945 data. The credit data were converted into real terms by dividing by the CPI.

${ }^{19}$ Both series were obtained from the IMF's International Financial Statistics data set. The share prices correspond to series code $15862 \ldots$ ZF ... and the CPI corresponds to series code $15864 \ldots$ ZF .... . The real share prices displayed in Figure 3 have been converted to real terms by dividing by the CPI.

\footnotetext{
${ }^{20}$ The call money rate was obtained from International Financial Statistics. The International Monetary Fund's gap data were found at http://www.imf.org/external/pubs/ft/weo/2010/01/weodata/weoselser.aspx?c=158\&t=1.

${ }^{21}$ The results are qualitatively similar for a range of values of the coefficients on inflation and the gap, and the smoothing parameter.
} 
because we are conjecturing what would have happened under the counterfactual monetary policy rule, (2.1). Such a counterfactual experiment would have a host of general equilibrium consequences that might have changed the realized data in profound ways. This is why we now leave the informal analysis of data and turn to the analysis of models next.

\section{A Simple Model For Interpreting the Evidence}

We begin our analysis in a model that is simple enough that the core results can be obtained analytically, without the distraction of all the frictions required to fit aggregate data well. The model is a version of the workhorse model used in Clarida, Gali and Gertler (1999) (CGG) and Woodford (2003).

We posit that the driving disturbance is a 'news shock', a disturbance to information about next period's innovation in technology. ${ }^{22}$ News that technology will improve in the future creates the expectation that future inflation will be low and this leads an inflation forecast targeting monetary authority to reduce the nominal rate of interest. This policy creates an immediate expansion in the economy. Although the expansion is associated with higher current marginal cost, inflation nevertheless drops in response to the lower future expected marginal costs.

We obtain our results in this section under two specifications for why there are frictions in prices. In one scenario ('pure sticky prices'), there are frictions directly in the setting of prices. In this scenario, wages are set flexibly in a competitive labor market. In the second scenario ('pure sticky wages'), prices are set flexibly, but are influenced by frictions in the setting of wages. Our model of wage frictions is the one proposed in Erceg, Henderson and Levin (2000) (EHL). The inefficient boom with low inflation occurs in both scenarios, though it does so across a wider range of parameter values under sticky wages.

The action of the monetary authority in reducing the nominal rate of interest in response to a news shock is exactly the wrong one in this model. Under the efficient monetary policy, the nominal rate of interest should not be decreased. Indeed, under pure sticky prices the nominal rate of interest should be increased substantially in response to a news shock. In the model, it is efficient for employment to be constant in each period, and for consumption to track the current realization of technology. The news shock triggers an expectation of higher future consumption, and the efficient rate of interest rises in order to offset the intertemporal substitution effects associated with an expectation of higher future consumption.

Household preferences in the model are:

$$
E_{t} \sum_{l=0}^{\infty} \beta^{l}\left[\log \left(C_{t+l}\right)-\frac{L_{t+l}^{1+\sigma_{L}}}{1+\sigma_{L}}\right],
$$

where $C_{t}$ denotes consumption and $L_{t}$ denotes employment. The household budget constraint is:

$$
P_{t} C_{t}+B_{t+1} \leq W_{t} L_{t}+R_{t-1} B_{t}+T_{t}
$$

\footnotetext{
${ }^{22}$ The empirical model of the next section includes news about periods further into the future than just one period. We work with one-period-ahead news in this section because our objective is to keep things sufficiently simple that the basic ideas are apparent.
} 
where $T_{t}$ denotes lump sum income from profits and government transfers, $R_{t}$ denotes the nominal rate of interest and $P_{t}, W_{t}$ denote the price level and wage rate, respectively.

Final goods, $Y_{t}$, are produced as a linear homogeneous function of $Y_{i t}, i \in(0,1)$ using the following Dixit-Stiglitz aggregator:

$$
Y_{t}=\left[\int_{0}^{1} Y_{l t}^{\frac{1}{\lambda_{f}}} d l\right]^{\lambda_{f}} .
$$

A representative, competitive final good producer buys the $i^{\text {th }}$ intermediate input at price, $P_{i t}$. The $i^{t h}$ input is produced by a monopolist, with production function

$$
Y_{i t}=\exp \left(a_{t}\right) L_{i t}
$$

Here, $L_{i t}$ denotes labor employed by the $i^{\text {th }}$ intermediate good producer. The $i^{\text {th }}$ producer is committed to sell whatever demand there is from the final good producers at the producer's price, $P_{i t}$. The producer receives a tax subsidy on wages in the amount, $(1-\nu) W_{t}$, where $\nu$ is set to extinguish the monopoly distortion in steady state. The subsidy is financed by lump sum taxes on households.

In the pure sticky price version of the model, wages are set flexibly in competitive markets and prices are set by the intermediate good monopolists, subject to Calvo-style frictions. In particular, with probability $\xi_{p}$ the $i^{t h}$ producer, $i \in(0,1)$, must keep its price unchanged to its value in the previous period and with the complementary probability the producer can set its price optimally. In the pure sticky wage version of the model, intermediate good producers set prices flexibly, as a fixed markup over marginal cost. Following EHL, we adopt a slight change in the specification of household utility in which households are monopolists in the supply differentiated labor services indexed by $j, j \in(0,1)$, and they set wages subject to Calvo-style frictions. With probability $\xi_{w}$ the wage of the $j^{\text {th }}$ type of specialized labor service cannot be changed from its value in the previous period. With the complementary probability the wage rate of the $j^{\text {th }}$ specialized labor service is set optimally.

We consider these two extreme specifications of price/wage setting frictions, because their simplicity allows us to derive results analytically. We consider the case with both sticky wages and prices, as well as other features useful for fitting aggregate data well, in the next section.

In our baseline analysis, we adopt the following law of motion for $a_{t}$ :

$$
a_{t}=\rho a_{t-1}+u_{t}, u_{t} \equiv \xi_{t}^{0}+\xi_{t-1}^{1} .
$$

Here, $u_{t}$ represents the white noise one-step-ahead error in forecasting $a_{t}$ based on its own past. We posit that this error is the sum of two mean-zero, white noise terms, $\xi_{t}^{0}$ and $\xi_{t-1}^{1}$, where

$$
E \xi_{t}^{0} a_{t-s}=E \xi_{t-1}^{1} a_{t-s}=0, s>0 .
$$

The subscript on $\xi_{t}^{j}$ indicates the date when this variable is revealed to agents in the model, $j=0,1$. Thus, at time $t$ agents become aware of $\xi_{t}^{0}$ and $\xi_{t}^{1}$. Here, $\xi_{t}^{0}$ represents the last piece of information received by agents about $u_{t}$ and $\xi_{t}^{1}$ represents the first piece of information about $u_{t+1}$. We refer to $\xi_{t}^{1}$ as 'news'. 
As is now standard, we express the household's log-linearized intertemporal Euler equation in deviation from what it is in the first-best equilibrium - in which the inflation rate is always zero and the interest rate is $R_{t}^{*}$ - as follows:

$$
\hat{x}_{t}=-E_{t}\left[\hat{R}_{t}-\hat{\pi}_{t+1}-R_{t}^{*}\right]+E_{t} \hat{x}_{t+1} .
$$

Here, $\hat{x}_{t}$ denotes the output gap, the percent deviation between the actual and efficient levels of output. Also, $\hat{R}_{t}$ and $\hat{\pi}_{t}$ denote the percent deviation of the gross nominal interest rate and of the gross inflation rate, respectively, from their values in steady state. Similarly, $R_{t}^{*}$ denotes the percent deviation of the gross nominal interest rate in the efficient equilibrium from its steady state.

As noted above, employment is constant in the efficient equilibrium and consumption is proportional to $\exp \left(a_{t}\right)$. In addition, inflation is zero. These properties, together with the assumption of unit intertemporal elasticity of substitution imply that, after linearization, $R_{t}^{*}$ corresponds to the expected change in $a_{t}:{ }^{23}$

$$
R_{t}^{*}=E_{t} a_{t+1}-a_{t}=(\rho-1) a_{t}+\xi_{t}^{1} .
$$

The shock to current productivity, $\xi_{t}^{0}$, enters via $a_{t}$ with a coefficient of $\rho-1$. In standard empirical applications which do not incorporate news shocks, the values of autoregressive coefficients like $\rho$ are estimated to be large (in a neighborhood of 0.9 ), and as a result $R_{t}^{*}$ is not very volatile. At the same time, note how the signal shock, $\xi_{t}^{1}$, appears with a unit coefficient in $R_{t}^{*}$. Evidently, the introduction of news shocks may increase the volatility of $R_{t}^{*}$ by an order of magnitude. The intuition is simple. A persistent shock that arrives without advance warning creates little incentive for intertemporal substitution. Such a shock creates only a small need to change the interest rate. By contrast, a signal that a persistent shock will occur in the future creates a strong intertemporal substitution motive which requires a correspondingly strong interest rate response.

The simplest representation of an interest rate rule that focuses on inflation is the following:

$$
\hat{R}_{t}=a_{\pi} E_{t} \hat{\pi}_{t+1} .
$$

This specification of the monetary policy rule, together with a particular labor market subsidy explained in Appendix A are structured so that the steady state of the efficient and actual equilibria coincide.

Completing the model requires an additional equation, a Phillips curve. We discuss the Phillips curve corresponding to pure sticky prices and pure sticky wages, respectively, in the following two sections. The derivation of the equilibrium conditions is tedious, but well known. For completeness, we include them in the appendix.

\footnotetext{
${ }^{23}$ It can be shown that the 'efficient' equilibrium is the Ramsey optimal equilibrium, in the case that there is no initial price dispersion. The Ramsey equilibrium considers just the private sector optimality and market clearing conditions, and leaves out a specification of the monetary poicy rule. In addition, there is a subsidy on the employment of labor, designed to address the distortions associated with monopoly power. The endogenous variables, including the tax subsidy are now underdetermined, as there are two more variables than equations. The Ramsey optimal equilibrium is the configuration of variables that satisfies the private sector equilibrium conditions and maximizes social welfare.
} 


\subsection{Pure Sticky Prices}

The equilibrium condition associated with price-setting is, after linearization:

$$
\hat{\pi}_{t}=\gamma \hat{x}_{t}+\beta E_{t} \hat{\pi}_{t+1}
$$

The slope of the Phillips curve with respect to the output gap, $\gamma$, is related to structural parameters as follows:

$$
\gamma=\frac{\left(1-\xi_{p}\right)\left(1-\beta \xi_{p}\right)}{\xi_{p}}\left(1+\sigma_{L}\right)
$$

where $\xi_{p}$ is the probability that a firm cannot change its price. Also, $1+\sigma_{L}$ represents the elasticity of firm marginal cost with respect to the output gap.

The price Phillips curve, (3.5), and IS relation, (3.2), after substituting out for $\hat{R}_{t}$ and $R_{t}^{*}$, represent two equations in two unknowns, $\hat{\pi}_{t}$ and $\hat{x}_{t}$. We posit the following solution,

$$
\begin{aligned}
& \hat{\pi}_{t}=\eta_{\pi} a_{t}+\phi_{\pi} \xi_{t}^{1} \\
& \hat{x}_{t}=\eta_{x} a_{t}+\phi_{x} \xi_{t}^{1},
\end{aligned}
$$

where $\eta_{\pi}, \phi_{\pi}, \eta_{x}, \phi_{x}$ are undetermined coefficients. The appendix uses straightforward, though tedious, algebra to solve for these objects. In the case of the response to $a_{t}$ (hence, $\left.\xi_{t}^{0}\right)$ :

$$
\eta_{x}=-\frac{\psi(1-\rho \beta)(1-\rho)}{\gamma}, \eta_{\pi}=\frac{\gamma}{1-\rho \beta} \eta_{x}
$$

Here,

$$
\psi=\frac{\gamma}{(1-\rho \beta)(1-\rho)+\left(a_{\pi}-1\right) \gamma \rho}>0
$$

It is evident that:

Proposition 3.1. $\eta_{x}, \eta_{\pi}<0$ for all admissible parameter values.

Simple substitution implies the following solution for the interest rate:

$$
\hat{R}_{t}=a_{\pi} \psi(\rho-1) \rho a_{t}+a_{\pi} \psi(\rho-1) \xi_{t}^{1},
$$

It is interesting to compare the actual interest rate response, $\hat{R}_{t}$ in (3.9), with the efficient interest rate response, $R_{t}^{*}$ in (3.3). We can see that if $a_{\pi}$ is sufficiently large, then $a_{\pi} \psi(\rho-1) \rho \rightarrow \rho-1$ and the interest rate response to $a_{t}$ (and, hence, to $\xi_{t}^{0}$ ) is efficient. For more moderate values of $a_{\pi}$ the interest rate at least has the right sign response to $a_{t}$, though the magnitude of that response is inefficiently weak. By contrast, the response of $R_{t}$ to $\xi_{t}^{1}$ is perverse. As noted above, the efficient interest rate displays a strong and positive response to $\xi_{t}^{1}$, while $R_{t}$ remains unchanged for $\rho=1$ and actually declines for $\rho<1$. To understand the perverse response of the interest rate to a news shock, we need to first discuss the reduced form parameters, $\eta_{x}, \eta_{\pi}, \phi_{\pi}, \phi_{x}$.

Consider $\eta_{x}, \eta_{\pi}$. Proposition 3.1 implies that $\xi_{t}^{0}$ drives both the output gap and inflation down. The intuition for this result is straightforward. Given the assumed time series representation for $a_{t}$, a positive shock to $\xi_{t}^{0}$ raises $a_{t}$ and creates the expectation that $a_{t}$ will be 
smaller in later periods. Relative to the efficient intertemporal consumption path in which $c_{t}=a_{t}$, households wish to reallocate consumption into the future. The monetary policy rule offsets the relative weakness in period $t$ demand by reducing the interest rate, $R_{t}$, but the response is not strong enough. As a result, period $t$ spending expands by less than the rise in $a_{t}$, accounting for the fall in the output gap in period $t$. The fall in the output gap implies weak labor demand and, hence, low labor costs. The reduction in costs accounts for the drop in inflation.

The fact, $\eta_{\pi}<0$, explains why $R_{t}$ drops in response to $\xi_{t}^{1}$. The news shock creates the expectation that technology will be launched on a temporary high in the next period, creating the expectation that inflation in the next period will be low. This is evident by evaluating (3.7) in $t+1$ and taking the period $t$ conditional expectation:

$$
E_{t} \hat{\pi}_{t+1}=\eta_{\pi}\left(\rho a_{t}+\xi_{t}^{1}\right)
$$

Because a positive disturbance to $\xi_{t}^{1}$ reduces anticipated inflation, and because our assumed monetary policy rule reacts to the inflation forecast, it follows that $R_{t}$ drops in response to a positive innovation in $\xi_{t}^{1}$.

The remaining reduced form parameters, $\phi_{\pi}$ and $\phi_{x}$, control the response of inflation and the output gap to a news shock, $\xi_{t}^{1}$. Appendix A establishes that these parameters are given by:

$$
\phi_{x}=\psi\left(a_{\pi}-1\right), \phi_{\pi}=\psi\left[-\beta(1-\rho)+\left(a_{\pi}-1\right) \gamma\right] .
$$

From the first expression, we see that $\phi_{x}>0$, so that the output gap always jumps with a positive signal about future productivity, $\xi_{t}^{1}$. The consumption smoothing motive and the rise in expected future consumption create a desire to increase current spending. In the efficient equilibrium the interest rate, $R_{t}^{*}$, increases sharply in order to keep spending equal to the unchanged current value of $a_{t}$. But, as discussed earlier, $R_{t}$ either does not respond at all in the limiting case, $\rho=1$, or it actually falls.

Turning to $\phi_{\pi}$, the impact of $\xi_{t}^{1}$ on $\hat{\pi}_{t}$ operates by way of its effects on current and future marginal cost. These effects can best be seen by solving the Phillips curve forward and making use of (3.8) and the law of motion for $a_{t}{ }^{24}$ :

$$
\begin{aligned}
\hat{\pi}_{t} & =\gamma\left[\hat{x}_{t}+\beta E_{t} \hat{x}_{t+1}+\beta^{2} E_{t} \hat{x}_{t+2}+\beta^{3} E_{t} \hat{x}_{t+3}+\ldots\right] \\
& =\gamma \eta_{\pi} \frac{1}{1-\beta \rho} a_{t}+\gamma \phi_{x} \xi_{t}^{1}+\gamma \frac{\beta \eta_{\pi}}{1-\beta \rho} \xi_{t}^{1}
\end{aligned}
$$

The first term involving $\xi_{t}^{1}, \gamma \phi_{x}$, pertains to the impact of a news shock on date $t$ marginal cost. This term is definitely positive because a positive period $t$ news shock raises the period $t$ output gap (recall, $\phi_{x}>0$ ). Thus, the impact of the news shock on $\hat{\pi}_{t}$ is positive if we only take into account period $t$ marginal cost (i.e., if $\beta=0$ ). Note that the second term involving $\xi_{t}^{1}$ is definitely negative (recall, $\eta_{\pi}<0$ ). This term reflects that a positive realization of $\xi_{t}^{1}$ signals a fall in future marginal costs. Thus, the net effect on current inflation of $\xi_{t}^{1}$ is ambiguous and so we must turn to a numerical example.

${ }^{24}$ The law of motion for $a_{t}$ implies

$$
E_{t} a_{t+j}=\rho^{j} a_{t}+\rho^{j-1} \xi_{t}^{1}
$$


The intuition sketched in this section suggests that the sign of the period $t$ inflation and output response to $\xi_{t}^{1}$ is likely to be sensitive to the assumptions about the time series representation of $a_{t}$. Suppose, for example, that $a_{t+1}>a_{t}$ after a positive shock to $\xi_{t}^{0}$. In this case, the shock to $\xi_{t}^{0}$ is likely to trigger a surge in the demand for goods, making $\eta_{x}$ and $\eta_{\pi}$ positive. ${ }^{25}$ This in turn suggests that in the period of a jump in $\xi_{t}^{1}$, firms would anticipate a rise in marginal cost not only in the current period but in future periods as well, so that $\pi_{t}$ would increase. We explore the robustness of our results to the assumptions about $a_{t}$ in the numerical experiments below.

\subsection{Pure Sticky Wages}

We now consider the case in which prices are flexible, but there are frictions in the setting of wages, as spelled out in EHL. They derive the following equilibrium condition:

$$
\hat{\pi}_{w, t}=\frac{\left(1-\xi_{w}\right)\left(1-\beta \xi_{w}\right)}{\xi_{w}\left(1+\sigma_{L} \frac{\lambda_{w}}{\lambda_{w}-1}\right)}\left[\left(1+\sigma_{L}\right) \hat{x}_{t}-\widehat{\bar{w}}_{t}\right]+\beta \hat{\pi}_{w, t+1}
$$

where $\pi_{w, t}$ denotes the gross growth rate of the nominal wage rate and $\bar{w}_{t}$ denotes the real wage, divided by technology, $\exp \left(a_{t}\right)$. As before, a hat over a variable indicates percent deviation from steady state. For completeness, (3.12) is derived in the appendix. The intuition for (3.12) is straightforward. The first object in the square brackets is the real marginal cost of work scaled by the technology shock, expressed in percent deviation from steady state. ${ }^{26}$ It is perhaps not surprising that when this object is higher than the scaled real wage, nominal wage growth is high. The growth rate of the scaled real wage, $\bar{w}_{t}$, the price level, the nominal wage rate and the state of technology are related by the following identity:

$$
\widehat{\bar{w}}_{t}=\widehat{\bar{w}}_{t-1}+\hat{\pi}_{w, t}-\hat{\pi}_{t}-\left(a_{t}-a_{t-1}\right)
$$

With flexible prices, (3.5) drops from the system. In addition, the fact that price setters set prices as a fixed markup over marginal cost implies $\widehat{\bar{w}}_{t}=0$ for all $t$. Imposing this condition and rearranging, we find, using (3.3):

$$
E_{t} \hat{\pi}_{w, t+1}=E_{t} \hat{\pi}_{t+1}+R_{t}^{*}
$$

Rewriting (3.12) taking $\widehat{\bar{w}}_{t}=0$ into account, we obtain:

$$
\hat{\pi}_{w, t}=\gamma_{w} \hat{x}_{t}+\beta \hat{\pi}_{w, t+1}
$$

\footnotetext{
${ }^{25}$ For an extensive discussion of the relationship between the time series representation of $a_{t}$ and the sign of the contemporaneous inflation and output response to $\xi_{t}^{0}$, see Christiano, Trabandt and Walentin (forthcoming).

${ }^{26}$ Let $c_{t}$ denote consumption, scaled by $\exp \left(a_{t}\right)$ and let $H_{t}$ denote hours worked. The appendix shows that $\hat{c}_{t}=\hat{H}_{t}=\hat{x}_{t}$. Then,

$$
\left(1+\sigma_{L}\right) \hat{x}_{t}=\hat{c}_{t}+\sigma_{L} \hat{H}_{t}
$$

which is the log-linear expansion of the (scaled) marginal rate of substitution between consumption and leisure when utility is logarithmic in consumption, and constant elasticity in labor.
} 
where

$$
\gamma_{w}=\frac{\left(1-\xi_{w}\right)\left(1-\beta \xi_{w}\right)}{\xi_{w}\left(1+\sigma_{L} \frac{\lambda_{w}}{\lambda_{w}-1}\right)}\left(1+\sigma_{L}\right) .
$$

We see an important distinction here between sticky wages and sticky prices. For a given degree of stickiness in wages and prices, i.e., $\xi_{p}=\xi_{w}$, slope of the wage Phillips curve, (3.15), is smaller than the slope of the price Phillips curve, (3.5). The intuition for this is simple. Because of constant returns to scale, firms in this economy have constant marginal costs. The marginal cost of supplying labor, by contrast, is increasing in labor and is steeper for larger $\sigma_{L}$. The price set by a monopolist with a steep marginal cost curve reacts less to a cost shock than does the price set by a monopolist with flat marginal cost. This effect on the monopolist's price response is magnified when demand is highly elastic and explains the presence of the elasticity of demand for labor in $(3.16), \lambda_{w} /\left(\lambda_{w}-1\right) .{ }^{2728}$

Using (3.14) to replace price inflation with wage inflation in the policy rule and the IS equation (see (3.4) and (3.2)),

$$
\begin{gathered}
\hat{R}_{t}=a_{\pi} E_{t}\left[\hat{\pi}_{w, t+1}-R_{t}^{*}\right] \\
\hat{x}_{t}=-E_{t}\left(\hat{R}_{t}-\hat{\pi}_{w, t+1}\right)+E_{t} \hat{x}_{t+1} .
\end{gathered}
$$

The three equilibrium conditions associated with the pure sticky wage model are the wage Phillips curve, (3.15), the policy rule, (3.17), and the IS equation, (3.18). This system can be solved for $\hat{x}_{t}, \hat{\pi}_{w, t}$, and $\hat{R}_{t}$. The implications for price inflation can then be deduced using (3.13) and $\widehat{\bar{w}}_{t}=0$.

The solution of the system can be represented as follows:

$$
\hat{\pi}_{w, t}=\eta_{\pi}^{w} a_{t}+\phi_{\pi}^{w} \xi_{t}^{1}, \hat{x}_{t}=\eta_{x}^{w} a_{t}+\phi_{x}^{w} \xi_{t}^{1}
$$

as in (3.10), with

$$
\hat{\pi}_{t}=\hat{\pi}_{w, t}-\left(a_{t}-a_{t-1}\right)
$$

according to (3.13). By this last expression, the impact of $\xi_{t}^{1}$ on $\hat{\pi}_{t}$ is simply $\phi_{\pi}^{w}$.

Section A.2 in the appendix establishes:

$$
\eta_{\pi}^{w}=\frac{\gamma_{w}}{1-\beta \rho} \eta_{x}^{w}, \eta_{x}^{w}=\frac{-a_{\pi}(1-\rho)(1-\beta \rho)}{(1-\rho)(1-\beta \rho)+\left(a_{\pi}-1\right) \rho \gamma_{w}}=-a_{\pi} \frac{\psi_{w}}{\gamma_{w}}(1-\rho)(1-\beta \rho)
$$

Evidently, the analog of proposition 3.1 holds for sticky wages:

Proposition 3.2. $\eta_{\pi}^{w}, \eta_{x}^{w}<0$ for all admissible parameter values.

\footnotetext{
${ }^{27}$ These results can be verified by considering the usual static monopoly diagram with price on the vertical axis and quantity on the horizontal, depicting demand, marginal revenue and marginal cost. Then, examine the effects of a given upward shift in marginal cost under two scenarios: one in which the marginal cost curve is flat and another in which the marginal cost curve is steep.

${ }^{28}$ The impact of increasing marginal costs on the slope of the price Phillips curve has received a lot of attention in the literature on firm-specific capital. To our knowledge, the effect was first noted in Sbordonne (2002), and also discussed in Altig, Christiano, Eichenbaum and Linde (2005), and de Walque, Smets, and Wouters, (2005).
} 
In addition, the appendix establishes:

$$
\phi_{x}^{w}=a_{\pi}\left(a_{\pi}-1\right) \psi_{w}, \phi_{\pi}^{w}=a_{\pi} \psi_{w}\left[-\beta(1-\rho)+\left(a_{\pi}-1\right) \gamma_{w}\right],
$$

where

$$
\psi_{w}=\frac{\gamma_{w}}{(1-\rho \beta)(1-\rho)+\left(a_{\pi}-1\right) \gamma_{w} \rho} .
$$

According to (3.21), the sign of $\phi_{x}^{w}$ is definitely negative. To see why, consider a scenario in which the period $t$ state of technology, $a_{t}$, is fixed and a signal arrives that $a_{t+1}$ will jump. That this can be expected to create expected deflation can be seen by considering the extreme case in which the nominal wage rate is literally fixed. In this case, constancy of $\bar{w}_{t}$ and $\bar{w}_{t+1}$ requires that an $x$-percent increase in technology be accompanied by an $x$-percent decrease in the contemporaneous price level. This implies that the current price level remains fixed after a one percent shock to $\xi_{t}^{1}$, while the period $t+1$ price level falls by one percent, i.e., $\pi_{t+1}<0$. This anticipated deflation, under a price inflation targeting rule with $a_{\pi}>1$, is met in a fall in $R_{t}$ sufficiently large so that the real interest rate also falls. This expansionary monetary reaction raises the period $t$ output gap by stimulating period $t$ spending. The wealth effect associated with the anticipated future rise in technology also helps to drive up spending.

By (3.20), the impact on period $t$ price inflation, $\pi_{t}$, of a signal, $\xi_{t}^{1}$, about future technology corresponds to $\phi_{\pi}^{w}$. As in the case of sticky prices, the sign of $\phi_{\pi}^{w}$ is ambiguous (see $(3.21))$. Present considerations alone (i.e., $\beta=0)$ make it positive. This is because the monetary expansion described in the previous paragraph increases the current marginal cost of working and this places upward pressure on $\pi_{w, t}$ according to the wage Phillips curve (3.15). Considerations of the future alone make $\phi_{\pi}^{w}$ negative. Intuitively, wage inflation in the next period, $\pi_{w, t+1}$, can be expected to fall with the anticipated jump in $a_{t+1}$ because of the negative sign of $\eta_{\pi}^{w}$ (see Proposition 3.2). The nature of the Calvo-style wage frictions suggest that $\pi_{w, t}$ should fall in anticipation of the fall in $\pi_{w, t+1}$ (see (3.15)). To determine the sign of $\phi_{\pi}^{w}$ for interesting values of the parameters requires numerical simulation.

Departing momentarily from our main theme, we note that in the pure sticky wage model, a monetary policy that relates the nominal rate of interest to price inflation does not optimize social welfare. As emphasized by EHL, the efficient allocations can be supported by a rule which replaces price inflation in the interest rate targeting rule with wage inflation. To see this, note that in this case the equilibrium conditions formed by the wage-targeting interest rate rule, (3.15) and (3.18) do not include the natural rate of interest. As a result the variables, $\hat{x}_{t}, \hat{R}_{t}$ and $\hat{\pi}_{w, t}$, determined by those equations evolve independently of the technology shock. In particular, the first best outcomes,

$$
\hat{x}_{t}=\hat{\pi}_{w, t}=0
$$

and $\hat{R}_{t}=0$ satisfy the equilibrium conditions with wage targeting. According to (3.20), the rate of price inflation, $\hat{\pi}_{t}$, is the negative of technology growth under a wage targeting monetary policy. Because the nominal wage rate is constant under this monetary policy, while the real wage must fluctuate with technology, it follows that optimal policy does not stabilize the high frequency movements in inflation in the pure sticky wage case. 


\subsection{Numerical Results}

In this section, we report numerical simulations of the period $t$ impact on inflation and output of a signal, $\xi_{t}^{1}$, that technology will expand by one percent in the next period. To investigate robustness of the analysis, we embed the time series representation of $a_{t}$ in (3.1) in the following more general representation:

$$
a_{t}=(\rho+\lambda) a_{t-1}-\rho \lambda+u_{t}, u_{t} \equiv \xi_{t}^{0}+\xi_{t-1}^{1},|\rho|,|\lambda| \leq 1 .
$$

The representation in (3.1) corresponds to (3.22) with $\lambda=0$. When $\rho+\lambda>1$, then (3.22) implies $a_{t}$ follows a 'hum-shape' pattern after an innovation to $a_{t}$. As indicated in our discussion of sticky prices, with $\lambda$ sufficiently large the model is expected to predict a rise in inflation in the wake of a positive signal, $\xi_{t}^{1}$. Numerical results are reported in Table 5 , and the value of $\lambda$ is indicated in the first column. Results for the forward looking rule, (3.4), are reported in Panel A of the table. As a further check on robustness, we also report results for the case where the interest rate responds to the contemporaneous rate of inflation, rather than to its expected value in the next period. Results for this case are presented in Panel B.

We adopt the following baseline parameterization of the model:

$$
\beta=1.03^{-1 / 4}, a_{\pi}=1.50, \xi_{w}=\xi_{p}=0.75, \lambda_{1}=0.9, \lambda_{2}=0, \sigma_{L}=1, \lambda_{w}=1.20 .
$$

In the pure sticky price version of the model, $\xi_{w}=0$ and $\xi_{p}=0.75$, while in the pure sticky wage version, $\xi_{w}=0.75$ and $\xi_{p}=0$.

Consider first the results for sticky prices in Panel A. Note that in the case stressed in the text, $\lambda=0$, inflation falls 2.8 basis points in the period that $\xi_{t}^{1}$ jumps by 0.01 , or 1 percent. At the same time, employment jumps by nearly one percent and the nominal rate of interest falls by 29 basis points. Under the efficient monetary policy, the interest rate jumps a full 100 basis points, employment does not change and inflation remains at zero. Evidently, the interest rate targeting rule that feeds back on expected inflation produces very inefficient results. It creates a boom where there should be none, and it does not stabilize inflation.

Note that as $\lambda$ increases, the interest rate targeting rule becomes more inefficient. For the largest value of $\lambda$ considered, employment increases 2.5 percent in the period of the signal shock. However, the cases ceases to be relevant from an empirical standpoint because inflation now increases in response to the signal shock.

Motivated by the fact that equilibrium models which do well empirically also incorporate sticky wages, we now consider the sticky wage case in Table 5 . Note that with sticky wages, inflation is predicted to fall and output rise, for all the values of $\lambda$ reported. Thus while the model with sticky prices is not robust to a hump-shape representation of $a_{t}$, one which also incorporates sticky wages can be expected to predict more robustly that inflation falls and the output gap rises, in response to a signal shock.

Now consider Panel B, which reports results for the contemporaneous specification of the interest rate rule. The results for $\pi_{t}, h_{t}, R_{t}$ are qualitatively similar to the results in Panel A. Figure 5 reports the period $t$ impact on the output gap $\left(\phi_{x}\right)$ and inflation $\left(\phi_{\pi}\right)$ of a one percent news shock under perturbations to our baseline model parameterization. In each case, we fix $\lambda=0$ and use the policy rule in (3.22). In addition, the parameter perturbations reported change only the value of the parameter indicated and hold the other parameters 
at their baseline value. As in Table 5, the sticky wage model is more robust in predicting

$\phi_{\pi}<0$. For example, if the price stickiness parameter, $\xi_{p}$, falls substantially below the benchmark value, then $\phi_{\pi}>0$. However, $\phi_{\pi}<0$ for all values of $\xi_{w}$ reported. Similarly, if $a_{\pi}$ is substantially above its value in the benchmark parameterization, then $\phi_{\pi}>0$ with pure sticky prices, but $\phi_{\pi}<0$ with pure sticky wages. Finally, $\phi_{x}>0$ for all parameterizations considered.

In summary, our benchmark sticky price model predicts that inflation drops and employment rises, in the period that a signal about a future technology expansion arrives. This resembles the pattern observed for stock market booms. When we depart substantially from the benchmark parameterization the model predicts a rise in inflation after a news shock. However, a model with pure sticky wages predicts much more robustly that inflation drops and the output gap rises in response to a signal shock. We conclude that models with sticky wages and sticky prices are likely to robustly predict that inflation falls and output rises in response to a signal shock. Models which simultaneously incorporate both sticky wages and sticky prices have a state variable and are not so easy to solve analytically as the case of pure sticky wages and pure sticky prices considered here. We turn to the model that incorporates both sticky wages and prices in the next section.

\section{Analysis in a Medium-Sized Model}

In this section, we consider a medium sized New Keynesian model fit to US postwar data by Bayesian methods. ${ }^{29}$ Relative to the material in the previous section, the analysis here has the disadvantage that it cannot be done analytically. On the other hand, the results may perhaps be taken more seriously because they are produced in a model which generates time series data that more closely resemble actual US data. In addition, in this model we are able to consider the impact of optimistic expectations about the future on the stock market (however, the model shares the shortcoming of most models in that it understates the magnitude of volatility in the stock market). The stock market is a variable that is missing in the analysis of the previous section. Finally, by adding the financial frictions proposed in BGG to our estimated model, we are able to consider interesting modifications to the inflation forecast targeting interest rate rule. We find that when we allow credit growth to play an independent role in that rule, one that goes beyond its role in forecasting inflation, then the interest rate targeting rule's tendency to produce excessive volatility in response to optimistic expectations about the future is reduced. We interpret this as evidence that credit growth is correlated with the natural rate of interest. The natural rate of interest is what one really wants in the interest rate targeting rule, and credit growth appears to be a good proxy, at least relative to shocks to expectations about the future.

\subsection{A Medium Sized Model}

The estimated model incorporates Calvo-style sticky prices and wages, habit persistence in preferences, variable capital utilization, adjustment costs in the change in investment. We do

\footnotetext{
${ }^{29}$ The model is a version of the one in Christiano, Eichenbaum and Evans (2005) and Smets and Wouters (2007).
} 
not display the shocks that were used in the estimation of the model. This section presents simulations of the model analogous to the simulations performed in the previous section. Our presentation of the model is limited to what is relevant for those simulations. As in EHL, we suppose that households supply a differentiated labor service, $l_{t, j}, j \in(0,1)$. Preferences of the household supplying the $j^{\text {th }}$ type of labor services are given by:

$$
E_{t}^{j} \sum_{l=0}^{\infty} \beta^{l}\left\{\log \left(C_{t+l}-0.75 C_{t+l-1}\right)-110 \frac{l_{t+l, j}^{2}}{2}\right\}, \beta=1.03^{-1 / 4}
$$

where $C_{t}$ denotes consumption. The household is a monopoly supplier of its type of labor service and sets the wage rate, $W_{j t}$, subject to the demand for $l_{t, j}$ and to the following friction. With probability, $\xi_{w}=0.80$ the household cannot reoptimize its wage and with the complementary probability it can set the wage optimally. In case it cannot reoptimize its wage, $W_{j t}$ is set as follows:

$$
W_{j t}=\bar{\pi} \mu_{z} W_{j t-1}
$$

where $\mu_{z}=1.0038$ is the steady state growth rate of the underlying shock to technology and $\bar{\pi}=1.006$ is the steady state rate of inflation. The household accumulates capital subject to the following technology:

$$
\bar{K}_{t+1}=(1-\delta) \bar{K}_{t}+\left(1-S\left(\frac{I_{t}}{I_{t-1}}\right)\right) I_{t}
$$

where $\bar{K}_{t}$ is the beginning of period $t$ physical stock of capital, and $I_{t}$ is period $t$ investment. The function $S$ is convex, with $S\left(\mu_{z}\right)=S^{\prime}\left(\mu_{z}\right)=0$ and $S^{\prime \prime}\left(\mu_{z}\right)=2.2$. The physical stock of capital is owned by the household and it rents capital services, $K_{t}$, to a competitive capital market:

$$
K_{t}=u_{t} \bar{K}_{t}
$$

where $u_{t}$ denotes the capital utilization rate. Increased utilization requires increased maintenance costs in terms of investment goods according to the following function

$$
a\left(u_{t}\right) \bar{K}_{t},
$$

where $a$ is increasing and convex, $a(1)=a^{\prime}(1)=0, a^{\prime \prime}(1)=0.02$ and $u_{t}$ is unity in nonstochastic steady state.

The households' specialized labor inputs are aggregated into a homogeneous labor service according to the following function

$$
L_{t}=\left[\int_{0}^{1}\left(l_{t, i}\right)^{\frac{1}{\lambda_{w}}} d i\right]^{\lambda_{w}}, \lambda_{w}=1.05
$$

A final good, $Y_{t}$, is produced by a representative, competitive firm according to the following technology

$$
Y_{t}=\left[\int_{0}^{1} Y_{l t}^{\frac{1}{\lambda_{f}}} d l\right]^{\lambda_{f}}, \lambda_{f}=1.20
$$


Here, $Y_{l t}$ is the $l^{\text {th }}$ intermediate good produced by a monopolist using the following technology:

$$
Y_{l, t}=\left(z_{t} A_{t} L_{l, t}\right)^{1-\alpha}\left(K_{l, t}^{\alpha}\right), z_{t}=\exp \left(\mu_{z} t\right), \alpha=0.4,
$$

where $K_{l, t}, L_{l, t}$ denote the capital and labor services used by the $l^{t h}$ monopolist. Also, $a_{t}=\log \left(A_{t}\right)$ and has law of motion analogous to the one in (3.1):

$$
a_{t}=0.9 a_{t-1}+\xi_{t}^{0}+\xi_{t-8}^{8}
$$

where $\xi_{t}^{0}, \xi_{t-8}^{8}$ are iid shocks which are uncorrelated with each other at all leads and lags, and with $a_{t-j}, j>0$. The shock, $\xi_{t-i}^{i}$, is observed by agents at date $t-i$. We refer to $\xi_{t-8}^{8}$ as a 'signals' about $a_{t}$ that arrives 8 quarters in advance.

The monopoly supplier of the intermediate good can reset its price optimally with probability $1-\xi_{p}, \xi_{p}=0.77$ and with probability $\xi_{p}$ it follows the following simple rule:

$$
P_{l, t}=\bar{\pi} P_{l, t-1}
$$

Monetary policy is governed by the following interest rate rule:

$$
\log \left(\frac{R_{t}}{R}\right)=\tilde{\rho} \log \left(\frac{R_{t-1}}{R}\right)+(1-\tilde{\rho}) \bar{R}_{t},
$$

where $R_{t}$ denotes the gross nominal rate of interest and

$$
\bar{R}_{t}=a_{\pi} E_{t} \log \left(\frac{\bar{\pi}_{t+1}}{\bar{\pi}}\right)+\frac{a_{y}}{4} \log \left(\frac{y_{t}}{y}\right),
$$

where $a_{\pi}=2.25, a_{y}=0.32$. Here, $y_{t}$ denotes gross domestic product (scaled by $z_{t}$ ) and $y$ denotes the corresponding steady state value. Also, $\tilde{\rho}=0.57$.

\subsection{Simulation}

Figure 6 presents the results of simulating a particular stock market boom-bust episode. In the first period a signal, $\xi_{t}^{8}>0$, arrives which creates the expectation that $a_{t}$ two years later will jump. However, that expectation is ultimately disappointed, because $\xi_{t+8}^{0}=-\xi_{t}^{8}$. Thus, in fact nothing real ever happens. The dynamics of the economy are completely driven by an optimistic expectation about future productivity, an expectation that is never realized. This experiment has a variety of interpretations. One is that people receive actual evidence that things will improve in the future, evidence that ultimately turns out to be false. Another is that they are irrationally optimistic about the future and they realize their error when the thing they expected does not happen.

In interpreting the results it is important to recognize that whether or not the signal is realized is irrelevant for the analysis in the periods before the anticipated event is supposed to occur. This is true whether we consider optimal policy, or policy that sets the interest rate according to a particular rule. This is because neither actual policy nor the policy maker implementing the optimal policy makes use of any information beyond what private agents know. 
We simulate the dynamic response of the economy under two circumstances. The thin line in Figure 6 corresponds to the response of the baseline model, the one defined in the previous subsection. The starred line corresponds to the response in the Ramsey-efficient equilibrium corresponding to the baseline model. To obtain the Ramsey equilibrium, we drop the monetary policy rule. The system is now undetermined, there being many constellations of stochastic processes that satisfy the remaining equilibrium conditions. The Ramsey equilibrium is the stochastic process for all the variables that optimizes a social welfare criterion constructed by integrating the utility of each type $j$ household, $j \in(0,1)$. The Ramsey equilibrium roughly corresponds to the equilibrium associated with the real business cycle model obtained by shutting down the wage and price setting frictions and by imposing that all intermediate good firms produce at the same level and each type $j$ worker works the same amount. We say 'roughly' here because deleting only one equation (i.e., the interest rate rule) does not provide enough degrees of freedom for the Ramsey equilibrium to literally extinguish all the frictions in the model. The Ramsey equilibrium forms a natural benchmark because it corresponds to the equilibrium with optimal monetary policy.

Note how the rise in investment, consumption, output and hours worked in the baseline equilibrium exceeds the corresponding rise in Ramsey equilibrium by a very substantial amount. This excess entirely reflects the suboptimality of the monetary policy rule, (4.1). Interestingly, the inflation rate in the boom is below its steady state value of roughly 2.5 percent annually, as in the examples of the previous section and as in the data. At the end of the boom, inflation rises a bit. According to the evidence in Adalid and Detken (2007) this is what typically happens in boom-bust episodes: inflation is low in the boom phase and then rises a little at the end.

The 3,1 panel in the figure displays the response of the price of capital in terms of consumption goods in the model. We interpret this as the price of equity in the model. Note that in the baseline model, the price of capital rises during the boom. In the Ramsey equilibrium, the price of capital actually falls. One way to understand this fall in the price of capital is that the real interest rate in the Ramsey equilibrium (the 'natural rate of interest', in the language of the previous section) rises sharply with the signal shock. The increased discounting of future payments to capital explains the fall in the price of capital. ${ }^{30}$ Monetary policy in the baseline equilibrium prevents the sharp rise in the interest rate. This is the heart of the problem with the monetary policy rule. The interest rate should be raised, as in the Ramsey equilibrium, but there is nothing in the monetary policy rule that produces this outcome. The most important variable in the interest rate targeting rule, inflation, actually drives the interest rate in the wrong direction. In effect, monetary policy is overly expansionary in the boom. This is what makes the stock market boom (actually, its is not a very strong boom) and what makes indicators of aggregate activity boom too. As Figure

\footnotetext{
${ }^{30}$ There is a second equilibrium condition that the price of capital must satisfy, in addition to the present discounted value relation. The second condition is the requirement that in competitive markets the price of capital must equal its marginal cost (i.e., the 'Tobin's q' relation). The signal shock creates the expectation that technology will be high in the future, and that investment will be strong in response. Given the adjustment cost specification, there is a gain to having increased investment in advance. This gain manifests itself in the form of a reduction in the current marginal cost of producing capital. Given our assumption that capital is traded in competitive markets, the reduction in cost is passed on in the form of a reduction in price.
} 
6 indicates, only a small part of the boom reflects the operation of optimistic expectations. The boom is primarily a phenomenon of loose monetary policy. Again, it bears repeating that the nature of the boom is independent of whether the signal is ultimately realized or not.

Interestingly, an outside observer might be tempted to interpret the rise in labor productivity during the boom as indicating that an actual improvement in technology is underway. In fact, the rise in productivity reflects a sharp rise in capital utilization. This phenomenon would be even greater if the model also incorporated variations in labor utilization.

In sum, an interest rate targeting rule that assigns substantial weight to inflation transforms what should be a modest expansion into a significant boom. The reason is that the monetary policy does not raise the interest rate sharply with the rise in the natural rate of interest. This problem can be fixed by setting the interest rate to the natural rate or, if that is deemed too difficult to measure, to some variable that is correlated with the natural rate. We explored the latter option. We added the financial frictions sketched by BGG to the baseline model, in order to obtain a model in which credit growth plays an important economic role. We found that when we simulate the resulting model's response to a signal shock, the equilibrium more closely approximates the corresponding Ramsey equilibrium if credit growth is introduced into the interest rate targeting rule, (4.1). In particular, we replace $\bar{R}_{t}$ in $(4.2)$ with:

$$
\bar{R}_{t}=\alpha_{\pi}\left[E_{t}\left(\pi_{t+1}\right)-\bar{\pi}\right]+\alpha_{y} \frac{1}{4} \log \left(\frac{y_{t}}{y}\right)+\alpha_{c} \times \text { nominal credit } \operatorname{growth}_{t}, \alpha_{c}=2.5,
$$

where credit is the quantity of loans obtained in the BGG model by entrepreneurs for the purpose of financing the purchase of capital. We find that in the baseline model, with $\alpha_{c}=0$, households would pay 0.23 percent of consumption forever to switch to the Ramsey equilibrium. We also find that households would pay 0.19 percent of consumption forever to switch to the equilibrium in which $\alpha_{c}=2.5$. We interpret this as evidence that including credit growth in the interest rate rule moves the economy a long way in the direction of the Ramsey equilibrium, in which monetary policy sets the interest rate to the natural rate of interest. These calculations have been done relative to signal shocks. A full evaluation of the policy of including credit in the interest rate targeting rule would evaluate the performance of this change when other shocks are present as well.

\section{Conclusion}

We have reviewed evidence which suggests that inflation is typically low in stock market booms and credit growth is high. The observation that inflation is low suggests that an interest rate targeting rule which focuses heavily on anticipated inflation may destabilize asset markets and perhaps the broader economy as well. The observation that credit growth is high in booms suggests that if credit growth is added to interest rate targeting rules, the resulting modified rule would moderate volatility in the real economy and in asset prices.

These inferences based on examination of the historical data constitute conjectures about the operating characteristics of counterfactual policies. To fully evaluate conjectures like 
these requires constructing and simulating a model economy. This is why we devoted substantial space model analysis. The model simulations reported in the paper lend support to our conjectures. 


\section{A. Appendix: Deriving the Equilibrium Conditions for the Simple Model}

We present a formal derivation of the simple model in section 3. Although the results are available elsewhere, we report them here for completeness. We suppose that the law of motion for log technology, $a_{t}$, has the following representation:

$$
a_{t}=\rho a_{t-1}+\xi_{t}^{0}+\xi_{t-1}^{1} .
$$

Household preferences are:

$$
E_{t} \sum_{l=0}^{\infty} \beta^{l}\left[\log \left(C_{t+l}\right)-\frac{L_{t+l}^{1+\sigma_{L}}}{1+\sigma_{L}}\right] .
$$

Households participate in spot competitive labor markets, where the wage rate, $W_{t}$, is set flexibly. In addition, in period $t$ households have access to a bond market in which the gross nominal rate of interest from $t$ to $t+1$ is denoted $R_{t}$. In addition, households purchase consumption goods, $C_{t}$, at price, $P_{t}$. The household budget constraint is:

$$
P_{t} C_{t}+B_{t+1} \leq W_{t} L_{t}+R_{t-1} B_{t}+T_{t}
$$

where $T_{t}$ denotes lump sum income from profits and government transfers. The first order necessary condition associated with the household's labor supply and savings decisions are:

$$
\psi_{L} L_{t}^{\sigma_{L}} C_{t}=\frac{W_{t}}{P_{t}}, \frac{1}{C_{t}}=\beta E_{t} \frac{1}{C_{t+1}} \frac{R_{t}}{\pi_{t+1}} .
$$

\section{A.1. Sticky Prices}

Final goods, $Y_{t}$, are produced as a linear homogeneous function of $Y_{i t}, i \in(0,1)$ using the following Dixit-Stiglitz aggregator:

$$
Y_{t}=\left[\int_{0}^{1} Y_{l t}^{\frac{1}{\lambda_{f}}} d l\right]^{\lambda_{f}} .
$$

The representative, competitive final good producer buys the $i^{\text {th }}$ intermediate input at price, $P_{i t}$. The $i^{t h}$ input is produced by a monopolist, with production function

$$
Y_{i t}=\exp \left(a_{t}\right) L_{i t} .
$$

Here, $L_{i t}$ denotes labor employed by the $i^{\text {th }}$ intermediate good producer. The $i^{\text {th }}$ producer is committed to sell whatever demand there is from the final good producers at the producer's price, $P_{i t}$. The producer receives a tax subsidy on wages in the amount, $(1-\nu) W_{t}$. The subsidy is financed by lump sum taxes on households. The $i^{\text {th }}$ intermediate good producer sets $P_{i, t}$ subject to Calvo frictions. Thus, in any period $1-\xi_{p}$ randomly selected producers may reset their price, and the remainder must set price according to:

$$
P_{i, t}=\left\{\begin{array}{cc}
P_{i, t-1} & \text { with probability } \xi_{p} \\
\tilde{P}_{t} & \text { with probability } 1-\xi_{p}
\end{array}\right.
$$

The resource constraint is:

$$
C_{t} \leq Y_{t} .
$$

We now describe the equations that characterize the private sector. 


\section{A.1.1. Private Sector Equilibrium}

We obtain a set of equations which characterize a private sector equilibrium. We then describe a log-linearization of those equations about steady state. It is easy to verify that each of the intermediate good producers which has an opportunity to set price in period $t$, does so as follows:

$$
\tilde{p}_{t}=\frac{K_{t}}{F_{t}}, \tilde{p}_{t} \equiv \frac{\tilde{P}_{t}}{P_{t}} .
$$

Here, $\tilde{P}_{t}$ denotes the price set by an optimizing intermediate good producer. Also,

$$
\begin{aligned}
K_{t} & =\lambda_{f} s_{t}+\beta \xi_{p} E_{t} \pi_{t+1}^{\varepsilon} K_{t+1} \\
F_{t} & =1+\beta \xi_{p} E_{t} \pi_{t+1}^{\varepsilon-1} F_{t+1} \\
s_{t} & =(1-\nu) \frac{\psi_{L} L_{t}^{\sigma_{L}} C_{t}}{A_{t}} .
\end{aligned}
$$

Here, $s_{t}$ denotes the (after subsidy, $\nu$ ) marginal cost of production, where the real wage has been replaced by the household's marginal rate of substitution between consumption and leisure (we impose a unit Frisch elasticity of labor supply).

Combining the final good production function with the first order condition of intermediate good producers implies

$$
P_{t}=\left[\int_{0}^{1} P_{i, t}^{\frac{1}{1-\lambda_{f}}} d i\right]^{1-\lambda_{f}} .
$$

Evaluating this integral taking into account the price set by current-period optimizers and taking into account that firms which do not reoptimize price are selected randomly, we obtain (after rearranging),

$$
\tilde{p}_{t}=\left[\frac{1-\xi_{p} \pi_{t}^{\frac{1}{\lambda_{f}-1}}}{1-\xi_{p}}\right]^{1-\lambda_{f}}
$$

We conclude

$$
\frac{K_{t}}{F_{t}}=\left[\frac{1-\xi_{p} \pi_{t}^{\frac{1}{\lambda_{f}-1}}}{1-\xi_{p}}\right]^{1-\lambda_{f}}
$$

In addition, the relationship between $Y_{t}$ and aggregate employment is given by

$$
Y_{t}=p_{t}^{*} L_{t}
$$

where law of motion for the price distortion is:

$$
p_{t}^{*}=\left[\left(1-\xi_{p}\right)\left(\frac{1-\xi_{p} \pi_{t}^{\frac{1}{\lambda_{f}-1}}}{1-\xi_{p}}\right)^{\lambda_{f}}+\frac{\xi_{p} \pi_{t}^{\frac{\lambda_{f}}{\lambda_{f}-1}}}{p_{t-1}^{*}}\right]^{-1}
$$

The resource constraint implies $C_{t}=Y_{t}$. 
We conclude that the equations which characterize a private sector equilibrium are:

$$
\begin{aligned}
\frac{1}{p_{t}^{*} L_{t}} & =\beta E_{t} \frac{1}{p_{t+1}^{*} L_{t+1} \exp \left(a_{t+1}-a_{t}\right)} \frac{R_{t}}{\pi_{t+1}} \\
\frac{1}{p_{t}^{*}} & =\left(1-\xi_{p}\right)\left(\frac{1-\xi_{p} \pi_{t}^{\frac{1}{\lambda_{f}-1}}}{1-\xi_{p}}\right)^{\lambda_{f}}+\frac{\xi_{p} \pi_{t}^{\frac{\lambda_{f}}{\lambda_{f}-1}}}{p_{t-1}^{*}} \\
F_{t} & =1+\beta \xi_{p} E_{t} \pi_{t+1}^{\frac{1}{\lambda_{f}-1}} F_{t+1} \\
K_{t} & =\lambda_{f}(1-\nu) L_{t}^{1+\sigma_{L}} p_{t}^{*}+\beta \xi_{p} E_{t} \pi_{t+1}^{\frac{\lambda_{f}}{\lambda_{f}-1}} K_{t+1} \\
\frac{K_{t}}{F_{t}} & =\left[\frac{1-\xi_{p} \pi_{t}^{\frac{1}{\lambda_{f}-1}}}{1-\xi_{p}}\right]^{1-\lambda_{f}} .
\end{aligned}
$$

Here, we have used the aggregate resource relation to substitute out for consumption. We assume that the labor market subsidy is set to eliminate the monopoly inefficiency in the labor market. That is,

$$
\lambda_{f}(1-\nu)=1
$$

Thus, there are 5 equilibrium conditions in 6 variables, $L_{t}, R_{t}, p_{t}^{*}, F_{t}, K_{t}, \pi_{t}$.

For a given value of steady state inflation, $\pi$, we use the steady state version of the above equations to solve for the steady state values of the other variables. In steady state, the 5 equations that characterize private sector equilibrium reduce to the following:

$$
\begin{aligned}
R & =\frac{\pi}{\beta}, p^{*}=\frac{\frac{1-\xi_{p} \pi^{\frac{\lambda_{f}}{\lambda_{f}-1}}}{1-\xi_{p}}}{\left(\frac{1-\xi_{p}(\pi)^{\frac{1}{\lambda_{f}-1}}}{1-\xi_{p}}\right)^{\lambda_{f}}} \\
F & =\frac{1}{1-\beta \xi_{p} \pi^{\frac{1}{\lambda_{f}-1}}}, K=\frac{(1-\nu) \lambda_{f} L^{1+\sigma_{L}} p^{*}}{1-\beta \xi_{p} \pi^{\frac{\lambda_{f}}{\lambda_{f}-1}}} \\
K & =F\left[\frac{1-\xi_{p} \pi^{\frac{1}{\lambda_{f}-1}}}{1-\xi_{p}}\right]^{1-\lambda_{f}}
\end{aligned}
$$

The first three equations allow one to compute $R, p^{*}, F$. Combining the last two:

$$
\frac{(1-\nu) \lambda_{f} L^{1+\sigma_{L}} p^{*}}{1-\beta \xi_{p} \pi^{\frac{\lambda_{f}}{\lambda_{f}-1}}}=F\left[\frac{1-\xi_{p} \pi^{\frac{1}{\lambda_{f}-1}}}{1-\xi_{p}}\right]^{1-\lambda_{f}},
$$


which can be solved for employment, $L$ :

$$
\begin{aligned}
L^{2} & =\frac{1-\beta \xi_{p} \pi^{\frac{\lambda_{f}}{\lambda_{f}-1}}}{(1-\nu) \lambda_{f} p^{*}} F\left[\frac{1-\xi_{p} \pi^{\frac{1}{\lambda_{f}-1}}}{1-\xi_{p}}\right]^{1-\lambda_{f}} \\
& =\frac{1}{(1-\nu) \lambda_{f} p^{*}} \frac{1-\beta \xi_{p} \pi^{\frac{\lambda_{f}}{\lambda_{f}-1}}}{1-\beta \xi_{p} \pi^{\frac{1}{\lambda_{f}-1}}}\left[\frac{1-\xi_{p} \pi^{\frac{1}{\lambda_{f}-1}}}{1-\xi_{p}}\right]^{1-\lambda_{f}}
\end{aligned}
$$

Finally, $K$ is computed using one of the two equations above in $K$.

Let $\hat{z}_{t}$ denote $d z_{t} / z$, for a small deviation, $d z_{t}=z_{t}-z$. Totally differentiating the 5 equilibrium conditions about steady state, we obtain:

$$
\begin{aligned}
-\left(\hat{p}_{t}^{*}+\hat{L}_{t}\right) & =\hat{R}_{t}-\hat{\pi}_{t+1}-\hat{p}_{t+1}^{*}-\hat{L}_{t+1}-\left(d a_{t+1}-d a_{t}\right) \\
\hat{p}_{t}^{*} & =\frac{\lambda_{f} \xi_{p}}{\lambda_{f}-1} \pi^{\frac{1}{\lambda_{f}-1}}\left[\left(\frac{1-\xi_{p} \pi^{\frac{1}{\lambda_{f}-1}}}{1-\xi_{p}}\right)^{\lambda_{f}-1} p^{*}-\pi\right] \hat{\pi}_{t}+\xi_{p} \pi^{\frac{\lambda_{f}}{\lambda_{f}-1}} \hat{p}_{t-1}^{*} \\
(1) \hat{F}_{t} & =\beta \xi_{p} E_{t}\left[\frac{1}{\lambda_{f}-1} \hat{\pi}_{t+1}+\hat{F}_{t+1}\right] \\
(2) \hat{K}_{t} & =\left(1-\beta \xi_{p}\right)\left[\left(1+\sigma_{L}\right) \hat{L}_{t}+\hat{p}_{t}^{*}\right]+\beta \xi_{p} E_{t}\left[\frac{\lambda_{f}}{\lambda_{f}-1} \hat{\pi}_{t+1}+\hat{K}_{t+1}\right] \\
(3) \hat{K}_{t} & =\frac{\xi_{p}}{1-\xi_{p}} \hat{\pi}_{t}+\hat{F}_{t}
\end{aligned}
$$

Substitute out for $\hat{K}_{t}$ from (3) into (2), and then (1) into the result, to obtain:

$$
\begin{aligned}
\hat{\pi}_{t} & =\kappa \hat{s}_{t}+\beta \hat{\pi}_{t+1} \\
\hat{s}_{t} & =\left(1+\sigma_{L}\right) \hat{L}_{t}+\hat{p}_{t}^{*}, \\
\kappa & =\frac{\left(1-\beta \xi_{p}\right)\left(1-\xi_{p}\right)}{\xi_{p}} .
\end{aligned}
$$

where $\hat{s}_{t}$ denotes the percent deviation of real marginal cost from its steady state. Note that when $\pi=1$, then the law of motion for the price distortion simplifies to $\hat{p}_{t}^{*}=\xi_{p} \hat{p}_{t-1}^{*}$. This implies that, as long as the system has been operating for some time, we can simply set $\hat{p}_{t}^{*}=0$ for all $t$. In this case, the linearized intertemporal equation can be written

$$
-\hat{L}_{t}=\hat{R}_{t}-\hat{\pi}_{t+1}-\hat{L}_{t+1}-\left(a_{t+1}-a_{t}\right),
$$

where we have dropped the ' $\mathrm{d}$ ' in front of the $a_{t}$ 's because the steady state cancels.

We take the efficient equilibrium to be the first-best, in which inflation is zero, $L_{t}=1$ and $C_{t}=A_{t}$. It can be shown this is the Ramsey efficient equilibrium when the labor subsidy is chosen to eliminate the distortions of monopoly power in the steady state and price distortions are zero in the initial period. 


\section{A.1.2. Interest Rate Rule Equilibrium}

We assume the monetary authority implements the following monetary policy rule

$$
\log \left(\frac{R_{t}}{R}\right)=a_{\pi} E_{t} \log \left(\pi_{t+1}\right),
$$

where the implicit target for inflation is its efficient level of zero. Substituting these assumptions in to the monetary policy rule and linearizing the latter about steady state, we obtain:

$$
\hat{R}_{t}=a_{\pi} E_{t} \hat{\pi}_{t+1}
$$

Equilibrium output is $y_{t}=\exp \left(a_{t}\right) p_{t}^{*} L_{t}$. In a zero inflation steady state $L=1$ and we may, to a first approximation, $p_{t}^{*}=1$. Thus, $x_{t}$, the ratio of actual output to efficient output is

$$
x_{t}=\frac{\exp \left(a_{t}\right) p_{t}^{*} L_{t}}{\exp \left(a_{t}\right)}=L_{t}
$$

and

$$
\hat{x}_{t}=\hat{L}_{t}
$$

where $\hat{x}_{t}$ is the percent deviation of actual output from Ramsey output. With these modifications, the intertemporal Euler equation can be written

$$
\hat{x}_{t}=-\left[\hat{R}_{t}-\hat{\pi}_{t+1}-R_{t}^{*}\right]+\hat{x}_{t+1} .
$$

Here, $x_{t}$ is the output gap.

We now explain the formulas for the solution to the simple model in section 3. Substituting out for $R_{t}$ and $R_{t}^{*}$ in the IS curve from the policy rule and the $R_{t}^{*}$ equation, we obtain:

$$
\begin{aligned}
& \hat{x}_{t}=-E_{t}\left[\left(a_{\pi}-1\right) \hat{\pi}_{t+1}-(\rho-1) a_{t}-\xi_{t}^{1}\right]+E_{t} \hat{x}_{t+1} \\
& \hat{\pi}_{t}=\gamma \hat{x}_{t}+\beta E_{t} \hat{\pi}_{t+1}
\end{aligned}
$$

where

$$
\gamma \equiv \kappa\left(1+\sigma_{L}\right)
$$

Substituting in the posited solution,

$$
\begin{aligned}
\eta_{x} a_{t}+\phi_{x} \xi_{t}^{1} & =-\left[\left(a_{\pi}-1\right) \eta_{\pi}\left[\rho a_{t}+\xi_{t}^{1}\right]-(\rho-1) a_{t}-\xi_{t}^{1}\right]+\eta_{x}\left[\rho a_{t}+\xi_{t}^{1}\right] \\
\eta_{\pi} a_{t}+\phi_{\pi} \xi_{t}^{1} & =\gamma\left[\eta_{x} a_{t}+\phi_{x} \xi_{t}^{1}\right]+\beta \eta_{\pi}\left[\rho a_{t}+\xi_{t}^{1}\right] .
\end{aligned}
$$

Collecting terms in $a_{t}$ and $\xi_{t}^{1}$ :

$$
\begin{aligned}
\eta_{x} & =-\left[\left(a_{\pi}-1\right) \eta_{\pi} \rho-(\rho-1)\right]+\eta_{x} \rho \\
\phi_{x} & =-\left[\left(a_{\pi}-1\right) \eta_{\pi}-1\right]+\eta_{x} \\
\eta_{\pi} & =\gamma \eta_{x}+\beta \eta_{\pi} \rho, \\
\phi_{\pi} & =\gamma \phi_{x}+\beta \eta_{\pi} .
\end{aligned}
$$


Using the first of these equations to simplify the second, we obtain:

$$
\begin{aligned}
\eta_{x} & =-\left(a_{\pi}-1\right) \eta_{\pi} \rho+\rho-1+\eta_{x} \rho \\
\phi_{x} & =\frac{\eta_{x}+1}{\rho} \\
\eta_{\pi} & =\gamma \eta_{x}+\beta \eta_{\pi} \rho \\
\phi_{\pi} & =\gamma \phi_{x}+\beta \eta_{\pi} .
\end{aligned}
$$

Solving the third equation:

$$
\eta_{\pi}=\frac{\gamma}{1-\rho \beta} \eta_{x}
$$

Using the latter to solve the first:

$$
\eta_{x}=-\frac{1}{1+\left(a_{\pi}-1\right) \frac{\gamma}{1-\rho \beta} \frac{\rho}{1-\rho}} .
$$

Now, consider $\phi_{\pi}$ :

$$
\begin{aligned}
\phi_{\pi} & =\gamma \phi_{x}+\beta \eta_{\pi}=\gamma \frac{\eta_{x}+1}{\rho}+\beta \frac{\gamma}{1-\rho \beta} \eta_{x} \\
& =\frac{\gamma}{\rho}\left\{1-\frac{1}{1-\rho \beta+\left(a_{\pi}-1\right) \frac{\gamma \rho}{1-\rho}}\right\} \\
& =\gamma \frac{-\beta(1-\rho)+\left(a_{\pi}-1\right) \gamma}{(1-\rho \beta)(1-\rho)+\left(a_{\pi}-1\right) \gamma \rho} .
\end{aligned}
$$

\section{A.2. Sticky Wages}

In this section, we interpret the labor, $L_{t}$, hired by intermediate good firms as supplied by 'labor contractors'. These contractors supply $L_{t}$ by combining a range of differentiated labor inputs, $h_{t, j}$, using the following technology, or 'aggregator function':

$$
L_{t}=\left[\int_{0}^{1}\left(h_{t, j}\right)^{\frac{1}{\lambda_{w}}} d j\right]^{\lambda_{w}}, 1 \leq \lambda_{w} .
$$

The labor contractors are perfectly competitive. They take the wage rate, $W_{t}$, of $L_{t}$ as given. They also take the wage rate, $W_{t, j}$, of the $j^{t h}$ labor type as given. Contractors choose inputs and outputs to maximize profits,

$$
W_{t} L_{t}-\int_{0}^{1} W_{t, j} h_{t, j} d j .
$$

The first order necessary condition for optimization is given by:

$$
h_{t, j}=\left(\frac{W_{t}}{W_{t, j}}\right)^{\frac{\lambda w}{1-\lambda_{w}}} L_{t} .
$$


Substituting the latter back into the labor aggregator function and rearranging, we obtain:

$$
W_{t}=\left[\int_{0}^{1} W_{t, j}^{\frac{1}{\lambda_{w}-1}} d j\right]^{\lambda_{w}-1}
$$

We now turn to the households. We adopt the 'indivisible labor'. Accordingly, suppose there is a large number of identical households. Each household has many members corresponding to each type, $j$, of labor. Each worker of type $j^{\text {th }}$ has an index, $l$, distributed uniformly over the unit interval, $[0,1]$, which indicates that worker's aversion to work. A type $j$ worker with index $l$ experiences utility:

$$
\log \left(C_{t}\right)-l^{\sigma_{L}}, \sigma_{L}>0
$$

if employed and

$$
\log \left(C_{t}\right)
$$

if not employed. The notation reflects that each worker in a household, whether employed or not and regardless of labor type, enjoys the same amount of consumption. This is the efficient arrangement, given our assumption that worker utility is separable in consumption and leisure and the household objective is to maximize the equally-weighted integral of worker utility.

The quantity of labor supplied by the representative household, $h_{t, j}$, is determined by (A.3). We suppose the household sends $j$-type workers with $0 \leq l \leq h_{t, j}$ to work and keeps those with $l>h_{t, j}$ out of the labor force. The equally weighted integral of utility over all $l \in[0,1]$ workers is:

Demand for labor, $h_{t, j}$, is determined by a monopoly union. Household

$$
\log \left(C_{t}\right)-\frac{h_{t, j}^{1+\sigma_{L}}}{1+\sigma_{L}}
$$

Overall household utility also integrates over all $j$-type workers:

$$
\log \left(C_{t}\right)-\int_{0}^{1} \frac{h_{t, j}^{1+\sigma_{L}}}{1+\sigma_{L}} d j
$$

It remains to explain how $C_{t}$ and $h_{t, j}$ are determined.

The wage rate of the $j^{\text {th }}$ type of labor, $W_{t, j}$, is determined outside the household by a monopoly union that represents all $j$-type workers across all households. The union's problem is discussed below. The household seeks to maximize the expected present discounted value of utility, (A.5), subject to the following budget constraint:

$$
P_{t} C_{t}+B_{t+1} \leq B_{t} R_{t-1}+\int_{0}^{1} W_{t, j} h_{t, j} d j+\text { Transfers and profits }{ }_{t} .
$$

The only thing for the household to do is choose $C_{t}$ and $B_{t+1}$. The first order necessary condition for optimization implies (A.1).

For each $j$ there is a monopoly union that represents all type $j$ workers across all households. The union is required to satisfy its demand curve, (A.3). It faces Calvo frictions in 
the setting of $W_{t, j}$. With probability $1-\xi_{w}$ a union can optimize the wage and with the complementary probability, $\xi_{w}$, it cannot, in which case,

$$
W_{t, j}=W_{t-1, j}
$$

With this specification, the wage of each type $j$ of labor is the same in the steady state. Because the union problem has no state variable, all unions with the opportunity to reoptimize in the current period face the same problem. In particular, such a union chooses the current value of the wage, $\tilde{W}_{t}$, to maximize:

$$
E_{t} \sum_{i=0}^{\infty}\left(\beta \xi_{w}\right)^{i} v_{t+i}\left[\tilde{W}_{t} h_{t+i}^{t}-\frac{\left(h_{t+i}^{t}\right)^{1+\sigma_{L}}}{\left(1+\sigma_{L}\right) v_{t+i}}\right]
$$

Here, $v_{t+i}$ denotes the marginal value assigned by each household (recall, they are all identical) to the wage. ${ }^{31}$ The household treats $v_{t}$ as an exogenous constant. In the above expression, $\xi_{w}$ appears in the discounting because the union's period $t$ decision only impacts on future histories in which it cannot reoptimize its wage. Also, $h_{t+i}^{t}$ denotes the level of employment in period $t+i$ of a union that had an opportunity to reoptimize the wage in period $t$ and did not reoptimize again in periods $t+1, \ldots, t+i$. By (A.3),

$$
h_{t+i}^{t}=\left(\frac{\tilde{W}_{t}}{W_{t+i}}\right)^{\frac{\lambda_{w}}{1-\lambda_{w}}} L_{t+i}=\left(\frac{w_{t}}{\pi_{w, t+1} \cdots \pi_{w, t+i}}\right)^{\frac{\lambda_{w}}{1-\lambda w}} L_{t+i}
$$

where

$$
w_{t} \equiv \frac{\tilde{W}_{t}}{W_{t}}, \bar{w}_{t} \equiv \frac{W_{t}}{\exp \left(a_{t}\right) P_{t}}, \chi_{t, i} \equiv\left\{\begin{array}{cl}
\frac{1}{\mu_{a, t+1} \mu_{a, t+2} \cdots \mu_{a, t+i} \pi_{t+1} \cdots \pi_{t+i}} & i \geq 1 \\
1 & i=0
\end{array} .\right.
$$

In (A.10), $\mu_{a, t}$ represents the growth rate of technology:

$$
\mu_{a, t}=\frac{\exp \left(a_{t}\right)}{\exp \left(a_{t-1}\right)}
$$

Using (A.9) to substitute out for $h_{t+i}^{t}$ in (A.8):

$$
E_{t} \sum_{i=0}^{\infty}\left(\beta \xi_{w}\right)^{i} v_{t+i}\left[\tilde{W}_{t}\left(\frac{\tilde{W}_{t}}{W_{t+i}}\right)^{\frac{\lambda w}{1-\lambda_{w}}} L_{t+i}-\frac{\left(\frac{\tilde{W}_{t}}{W_{t+i}}\right)^{\frac{\lambda w}{1-\lambda_{w}}\left(1+\sigma_{L}\right)} L_{t+i}^{1+\sigma_{L}}}{\left(1+\sigma_{L}\right) v_{t+i}}\right]
$$

Differentiating with respect to $\tilde{W}_{t}$ we obtain, after rearranging,

$$
E_{t} \sum_{i=0}^{\infty}\left(\beta \xi_{w}\right)^{i} \frac{h_{t+i}^{t}}{c_{t+i}}\left[\bar{w}_{t} w_{t} \chi_{t, i}-\lambda_{w} M R S_{t+i}^{t}\right]
$$

\footnotetext{
${ }^{31}$ The object, $v_{t}$, It is the multiplier on the household budget constraint, (A.6), in the Lagrangian representation of its problem.
} 
where

$$
c_{t} \equiv \frac{C_{t}}{\exp \left(a_{t}\right)}, v_{t+j}=\frac{1}{P_{t+j} C_{t+j}} .
$$

Also, $M R S_{t+i}^{t}$ in (A.11) denotes the (scaled) cost of working for the marginal worker in period $t+i$ whose wage was reoptimized in period $t$ and not again reoptimized in periods $t+1, t+2, \ldots, t+i$ :

$$
M R S_{t+i}^{t} \equiv \frac{\left(h_{t+i}^{t}\right)^{\sigma_{L}}}{\exp \left(a_{t+i}\right) P_{t+i} v_{t+i}}=c_{t+i}\left(h_{t+i}^{t}\right)^{\sigma_{L}}
$$

According to (A.11), the union seeks to set the wage to a markup, $\lambda_{w}$, over the cost of working of the marginal worker, on average.

We now expand (A.11) about a steady state in which

$$
w_{t}=1, \chi_{i}=1, \text { all } i, \bar{w}_{t}=\lambda_{w} M R S, \pi_{t}=1, \pi_{w, t}=1 .
$$

It is convenient to obtain some preliminary results. Note,

$$
\begin{aligned}
\hat{\chi}_{t, i} & =\left\{\begin{array}{cc}
-\left(\hat{\mu}_{a, t+1}+\hat{\mu}_{a, t+2}+\cdots+\hat{\mu}_{a, t+i}\right)-\hat{\pi}_{t+1}-\cdots-\hat{\pi}_{t+i} & i>0 \\
0 & i=0
\end{array},\right. \\
\widehat{M R S}_{t+i}^{t} & =\hat{c}_{t+i}+\sigma_{L} \hat{H}_{t+i}+\sigma_{L}\left(\hat{h}_{t+i}^{t}-\hat{H}_{t+i}\right),
\end{aligned}
$$

and, from (A.9),

$$
\hat{h}_{t+i}^{t}-\hat{H}_{t+i}=\left\{\begin{array}{cc}
\frac{\lambda_{w}}{1-\lambda_{w}}\left(\hat{w}_{t}-\hat{\pi}_{w, t+1} \cdots-\hat{\pi}_{w, t+i}\right) & i>0 \\
\frac{\lambda_{w}}{1-\lambda_{w}} \hat{w}_{t} & i=0
\end{array} .\right.
$$

We can write the discounted sum of the marginal cost of working as follows:

$$
S_{M R S, t} \equiv \sum_{i=0}^{\infty}\left(\beta \xi_{w}\right)^{i} \widehat{M R S}_{t+i}^{t}=S_{o, t}+\sigma_{L} \frac{\lambda_{w}}{1-\lambda_{w}} \frac{1}{1-\beta \xi_{w}}\left[\hat{w}_{t}-S_{w, t}\right] .
$$

Here,

$$
\begin{aligned}
S_{o, t} & \equiv \sum_{i=0}^{\infty}\left(\beta \xi_{w}\right)^{i}\left[\hat{c}_{t+i}+\sigma_{L} \hat{H}_{t+i}\right]=\hat{c}_{t}+\sigma_{L} \hat{H}_{t}+\beta \xi_{w} S_{o, t+1} \\
S_{w, t} & \equiv \sum_{i=1}^{\infty}\left(\beta \xi_{w}\right)^{i} \hat{\pi}_{w, t+i}=\beta \xi_{w} \hat{\pi}_{w, t+1}+\beta \xi_{w} S_{w, t+1} .
\end{aligned}
$$

The following expression is also useful:

$$
\begin{aligned}
S_{\chi, t} & =\sum_{i=1}^{\infty}\left(\beta \xi_{w}\right)^{i} \hat{\chi}_{t, i}=\frac{1}{1-\beta \xi_{w}} \sum_{i=1}^{\infty}\left(\beta \xi_{w}\right)^{i}\left[-\hat{\mu}_{a, t+i}-\hat{\pi}_{t+i}\right] \\
& =\frac{\beta \xi_{w}}{1-\beta \xi_{w}}\left[-\hat{\mu}_{a, t+1}-\hat{\pi}_{t+1}\right]+\beta \xi_{w} S_{\chi, t+1} .
\end{aligned}
$$


Because the object in square brackets in (A.11) is zero in steady state, the expansion of (A.11) does not require expanding the expression outside the square bracket. Taking this and $\bar{w}=\lambda_{w} M R S$ into account, the expansion of (A.11) is:

$$
0=\frac{1}{1-\beta \xi_{w}}\left(\widehat{\bar{w}}_{t}+\hat{w}_{t}\right)+S_{\chi, t}-S_{M R S, t} .
$$

We now deduce the restriction across wages implied by (A.4). Using (A.7) and the fact that non-optimizing unions are selected at random, (A.4) reduces to:

$$
W_{t}=\left[\left(1-\xi_{w}\right)\left(\tilde{W}_{t}\right)^{\frac{1}{1-\lambda_{w}}}+\xi_{w}\left(W_{t-1}\right)^{\frac{1}{1-\lambda_{w}}}\right]^{1-\lambda_{w}} .
$$

Divide by $W_{t}$ and use (A.10):

$$
1=\left(1-\xi_{w}\right)\left(w_{t}\right)^{\frac{1}{1-\lambda w}}+\xi_{w}\left(\frac{1}{\pi_{w, t}}\right)^{\frac{1}{1-\lambda w}} .
$$

Log-linearize this expression about steady state, to obtain:

$$
\hat{w}_{t}=\frac{\xi_{w}}{1-\xi_{w}} \hat{\pi}_{w, t} .
$$

Replace $S_{M R S, t}$ in (A.17) using (A.13) and then substitute out for $\hat{w}_{t}$ using the previous expression:

$$
\begin{aligned}
& \frac{1}{1-\beta \xi_{w}} \widehat{\bar{w}}_{t}+\frac{1}{1-\beta \xi_{w}} \frac{\xi_{w}}{1-\xi_{w}} \hat{\pi}_{w, t}+S_{\chi, t} \\
= & S_{o, t}+\sigma_{L} \frac{\lambda_{w}}{1-\lambda_{w}} \frac{1}{1-\beta \xi_{w}} \frac{\xi_{w}}{1-\xi_{w}} \hat{\pi}_{w, t}-\sigma_{L} \frac{\lambda_{w}}{1-\lambda_{w}} \frac{1}{1-\beta \xi_{w}} S_{w, t}
\end{aligned}
$$

Multiply (A.18) evaluated at $t+1$ by $\beta \xi_{w}$ and subtract the result from (A.18) evaluated at $t$ to obtain:

$$
\begin{aligned}
& \frac{1}{1-\beta \xi_{w}}\left(\widehat{\bar{w}}_{t}-\beta \xi_{w} \widehat{\bar{w}}_{t+1}\right)+\frac{1}{1-\beta \xi_{w}} \frac{\xi_{w}}{1-\xi_{w}}\left(\hat{\pi}_{w, t}-\beta \xi_{w} \hat{\pi}_{w, t+1}\right)+\left(S_{\chi, t}-\beta \xi_{w} S_{\chi, t+1}\right) \\
= & \left(S_{o, t}-\beta \xi_{w} S_{o, t+1}\right)+\sigma_{L} \frac{\lambda w}{1-\lambda_{w}} \frac{1}{1-\beta \xi_{w}} \frac{\xi_{w}}{1-\xi_{w}}\left(\hat{\pi}_{w, t}-\beta \xi_{w} \hat{\pi}_{w, t+1}\right) \\
& -\sigma_{L} \frac{\lambda_{w}}{1-\lambda_{w}} \frac{1}{1-\beta \xi_{w}}\left(S_{w, t}-\beta \xi_{w} S_{w, t+1}\right)
\end{aligned}
$$

Simplify this expression using (A.14), (A.15) and (A.16):

$$
\begin{aligned}
& \frac{1}{1-\beta \xi_{w}}\left(\widehat{\bar{w}}_{t}-\beta \xi_{w} \widehat{\bar{w}}_{t+1}\right)+\frac{1}{1-\beta \xi_{w}} \frac{\xi_{w}}{1-\xi_{w}}\left(\hat{\pi}_{w, t}-\beta \xi_{w} \hat{\pi}_{w, t+1}\right) \\
& -\frac{\beta \xi_{w}}{1-\beta \xi_{w}}\left(\hat{\mu}_{a, t+1}+\hat{\pi}_{t+1}\right) \\
= & \hat{c}_{t}+\sigma_{L} \hat{H}_{t}+\sigma_{L} \frac{\lambda_{w}}{1-\lambda_{w}} \frac{1}{1-\beta \xi_{w}} \frac{\xi_{w}}{1-\xi_{w}}\left(\hat{\pi}_{w, t}-\beta \xi_{w} \hat{\pi}_{w, t+1}\right) \\
& -\sigma_{L} \frac{\lambda_{w}}{1-\lambda_{w}} \frac{1}{1-\beta \xi_{w}} \beta \xi_{w} \hat{\pi}_{w, t+1}
\end{aligned}
$$


The relationship between wage and price inflation, the change in the real wage and technology growth is given by:

$$
\widehat{\bar{w}}_{t}=\widehat{\bar{w}}_{t-1}+\hat{\pi}_{w, t}-\hat{\pi}_{t}-\hat{\mu}_{a, t} .
$$

Use this to substitute out for $\hat{\pi}_{t+1}$ in (A.19):

$$
\begin{aligned}
& \frac{1}{1-\beta \xi_{w}}\left(\widehat{\bar{w}}_{t}-\beta \xi_{w} \widehat{\bar{w}}_{t+1}\right)+\frac{1}{1-\beta \xi_{w}} \frac{\xi_{w}}{1-\xi_{w}}\left(\hat{\pi}_{w, t}-\beta \xi_{w} \hat{\pi}_{w, t+1}\right)-\frac{\beta \xi_{w}}{1-\beta \xi_{w}}\left(\widehat{\bar{w}}_{t}+\hat{\pi}_{w, t+1}-\widehat{\bar{w}}_{t+1}\right) \\
= & \hat{c}_{t}+\sigma_{L} \hat{H}_{t}+\sigma_{L} \frac{\lambda_{w}}{1-\lambda_{w}} \frac{1}{1-\beta \xi_{w}} \frac{\xi_{w}}{1-\xi_{w}}\left(\hat{\pi}_{w, t}-\beta \xi_{w} \hat{\pi}_{w, t+1}\right)-\sigma_{L} \frac{\lambda_{w}}{1-\lambda_{w}} \frac{1}{1-\beta \xi_{w}} \beta \xi_{w} \hat{\pi}_{w, t+1}
\end{aligned}
$$

Collecting terms in $\widehat{\bar{w}}_{t}, \widehat{\bar{w}}_{t+1}, \hat{\pi}_{w, t}, \hat{\pi}_{w, t+1}$ :

$$
\begin{aligned}
& \widehat{\bar{w}}_{t}+\frac{1}{1-\beta \xi_{w}} \frac{\xi_{w}}{1-\xi_{w}}\left(1-\sigma_{L} \frac{\lambda_{w}}{1-\lambda_{w}}\right) \hat{\pi}_{w, t}=\hat{c}_{t}+\sigma_{L} \hat{H}_{t} \\
& +\frac{\beta \xi_{w}}{1-\beta \xi_{w}}\left(\frac{\xi_{w}}{1-\xi_{w}}+1-\sigma_{L} \frac{\lambda_{w}}{1-\lambda_{w}}\left[\frac{\xi_{w}}{1-\xi_{w}}+1\right]\right) \hat{\pi}_{w, t+1}
\end{aligned}
$$

or, after simplifying,

$$
\begin{aligned}
& \widehat{\bar{w}}_{t}+\frac{1}{1-\beta \xi_{w}} \frac{\xi_{w}}{1-\xi_{w}}\left(1-\sigma_{L} \frac{\lambda_{w}}{1-\lambda_{w}}\right) \hat{\pi}_{w, t}=\hat{c}_{t}+\sigma_{L} \hat{H}_{t} \\
& +\frac{\beta \xi_{w}}{1-\beta \xi_{w}} \frac{1}{1-\xi_{w}}\left(1-\sigma_{L} \frac{\lambda_{w}}{1-\lambda_{w}}\right) \hat{\pi}_{w, t+1} .
\end{aligned}
$$

Let

$$
\kappa_{w}=\frac{\left(1-\xi_{w}\right)\left(1-\beta \xi_{w}\right)}{\beta \xi_{w}} .
$$

Multiply the previous expression by $\kappa_{w}$ and rearrange:

$$
\left(1-\sigma_{L} \frac{\lambda_{w}}{1-\lambda_{w}}\right) \hat{\pi}_{w, t}=\kappa_{w}\left(\hat{c}_{t}+\sigma_{L} \hat{H}_{t}-\widehat{\bar{w}}_{t}\right)+\left(1-\sigma_{L} \frac{\lambda_{w}}{1-\lambda_{w}}\right) \hat{\pi}_{w, t+1} .
$$

Divide both sides by the coefficient on $\hat{\pi}_{w, t}$, we obtain the wage Phillips curve:

$$
\hat{\pi}_{w, t}=\frac{\kappa_{w}}{1+\sigma_{L} \frac{\lambda_{w}}{\lambda_{w}-1}}\left(\hat{c}_{t}+\sigma_{L} \hat{H}_{t}-\widehat{\bar{w}}_{t}\right)+\beta \hat{\pi}_{w, t+1}
$$




\section{References}

[1] Adalid, Ramon, and Carsten Detken, 2007, 'Liquidity Shocks and Asset Price Boom/Bust Cycles,' European Central Bank working paper number 732.

[2] Alexopoulos, Michelle, 2007, "Believe it Or Not! The 1930s Was a Technologically Progressive Decade," unpublished manuscript, Department of Economics, University of Toronto.

[3] Barlevy, Gadi, 2008, "A leverage-based model of speculative bubbles," Federal Reserve Bank of Chicago working paper number 2008-01.

[4] Barsky, Robert B. and Eric R. Sims, 2010, "News Shocks and Business Cycles," July 22, manuscript, University of Notre Dame.

[5] Bernanke, Ben S. and Mark Gertler, 1999, "Monetary Policy and Asset Volatility," Federal Reserve Bank of Kansas City Economic Review, Fourth Quarter, 84(4), pp. $17-52$.

[6] Beaudry, Paul and Franck Portier, 2004, "An exploration into Pigou's theory of cycles," Journal of Monetary Economics, volume 51, Issue 6 pp. 1183-1216, September.

[7] Beaudry, Paul and Franck Portier, 2006, "News, Stock Prices and Economic Fluctuations," The American Economic Review, Vol. 96, No. 4, September, pp. 1293-1307.

[8] Bernanke, Ben S. and Mark Gertler, 2001, "Should Central Banks Respond to Movements in Asset Prices?", The American Economic Review, Vol. 91, No. 2, Papers and Proceedings of the Hundred Thirteenth Annual Meeting of the American Economic Association (May), pp. 253-257.

[9] Bernanke, Ben, Mark Gertler and Simon Gilchrist, 1999, "The Financial Accelerator in a Quantitative Business Cycle Framework," Handbook of Macroeconomics, edited by John B. Taylor and Michael Woodford, pp. 1341-93, Amsterdam, New York and Oxford: Elsevier Science, North-Holland.

[10] Bordo, Michael D. and David C. Wheelock, 2004, "Monetary Policy and Asset Prices: A Look Back at Past U.S. Stock Market Booms," Federal Reserve Bank of St. Louis Review, November/December, 86(6), pp. 19-44.

[11] Bordo, Michael D. and David C. Wheelock, 2007, Stock Market Booms and Monetary Policy in the Twentieth Century, Federal Reserve Bank of St. Louis Review, March/April, 89(2), pp. 90-122.

[12] Cecchetti, Stephen G., Hans Genberg, John Lipsky and Sushil Wadhwani, 2000, "Asset Prices and Central Bank Policy," London: Center for Economic Policy Research (released in working paper form as Geneva Report on the World Economy No. 2).

[13] Christiano, Lawrence J., Martin Eichenbaum and Charles L. Evans, 2005, "Nominal Rigidities and the Dynamic Effects of a Shock to Monetary Policy," Journal of Political Economy, Vol. 113(1), pages 1-45. 
[14] Christiano, Lawrence J. and Ippei Fujiwara, 2006, "The Bubble, Overinvestment, Reduction in Working Hours, and the Lost Decade," (in Japanese) Bank of Japan Working Papers Series 06-J-8.

[15] Christiano, Lawrence J., Roberto Motto and Massimo Rostagno, 2007, "Two Reasons Why Money and Credit May be Useful in Monetary Policy," NBER working paper number 13502.

[16] Christiano, Lawrence, Cosmin Ilut, Roberto Motto, and Massimo Rostagno, 2008, "Monetary Policy and Stock Market Boom-Bust Cycles," European Central Bank Working Paper no. 955, October.

[17] Christiano, Lawrence, Mathias Trabandt and Karl Walentin, forthcoming, "DSGE Models for Monetary Policy," in Benjamin Friedman and Michael Woodford, Handbook of Monetary Economics.

[18] Clarida, Richard, Jordi Gali and Mark Gertler, 1999, "The Science of Monetary Policy: A New Keynesian Perspective", Journal of Economic Literature, Vol. XXXVII (December), pages 1661-1707.

[19] Eichengreen, Barry, 2009, "The Financial Crisis and Global Policy Reforms," October.

[20] Erceg, Christopher J., Henderson, Dale, W. and Andrew T. Levin, 2000, "Optimal Monetary Policy with Staggered Wage and Price Contracts," Journal of Monetary Economics, Vol. 46, pages 281-313.

[21] Evans, Charles, 2010, "Letter to 10 Senators Discussing Financial Reform," http://www.chicagofed.org/webpages/utilities/newsroom/news_releases/ 2010/03.04_ce_letter_release.cfm

[22] Geanakoplos, John, 2009, "The Leverage Cycle," in Daron Acemoglu, Kenneth Rogoff and Michael Woodford, eds., NBER Macroeconomic Annual 2009, vol. 24: 1-65, University of Chicago Press (erratum: Cowles Foundation Paper no. 1304).

[23] Hirtle, Beverly, Til Schuermann, and Kevin Stiroh, 2009, "Macroprudential Supervision of Financial Institutions: Lessons from the SCAP," Federal Reserve Bank of New York Staff Report number 409, November.

[24] Ramey, Valerie, 2009, "Defense News Shocks, 1939-2008: Estimates Based on News Sources," October, unpublished manuscript.

[25] Ramey, Valerie, forthcoming, "Identifying Government Spending Shocks: It's All in the Timing," Quarterly Journal of Economics.

[26] Schwert, G. William, 1990, "Indexes of United States Stock Prices from 1802 to 1987," Journal of Business, 63 (July) 399-426. 
[27] Shirakawa, Masaaki, 2010, "Revisiting the Philosophy behind Central Bank Policy," Speech at the Economic Club of New York, April 22 (2010, available at http://www.boj.or.jp/en/type/press/koen07/ko1004e.htm).

[28] Smets, Frank, and Raf Wouters, 2007, "Shocks and Frictions in US Business Cycles," American Economic Review, Vol. 97(3), pages 586-606.

[29] White, William R., 2009, "Should monetary policy lean or clean?," BIS working paper No. 205, April.

[30] Woodford, Michael, 2003, "Interest and Prices: Foundations of a Theory of Monetary Policy", Princeton University Press, 2003. 
Figure 1: Data for 19th and Early 20th Century

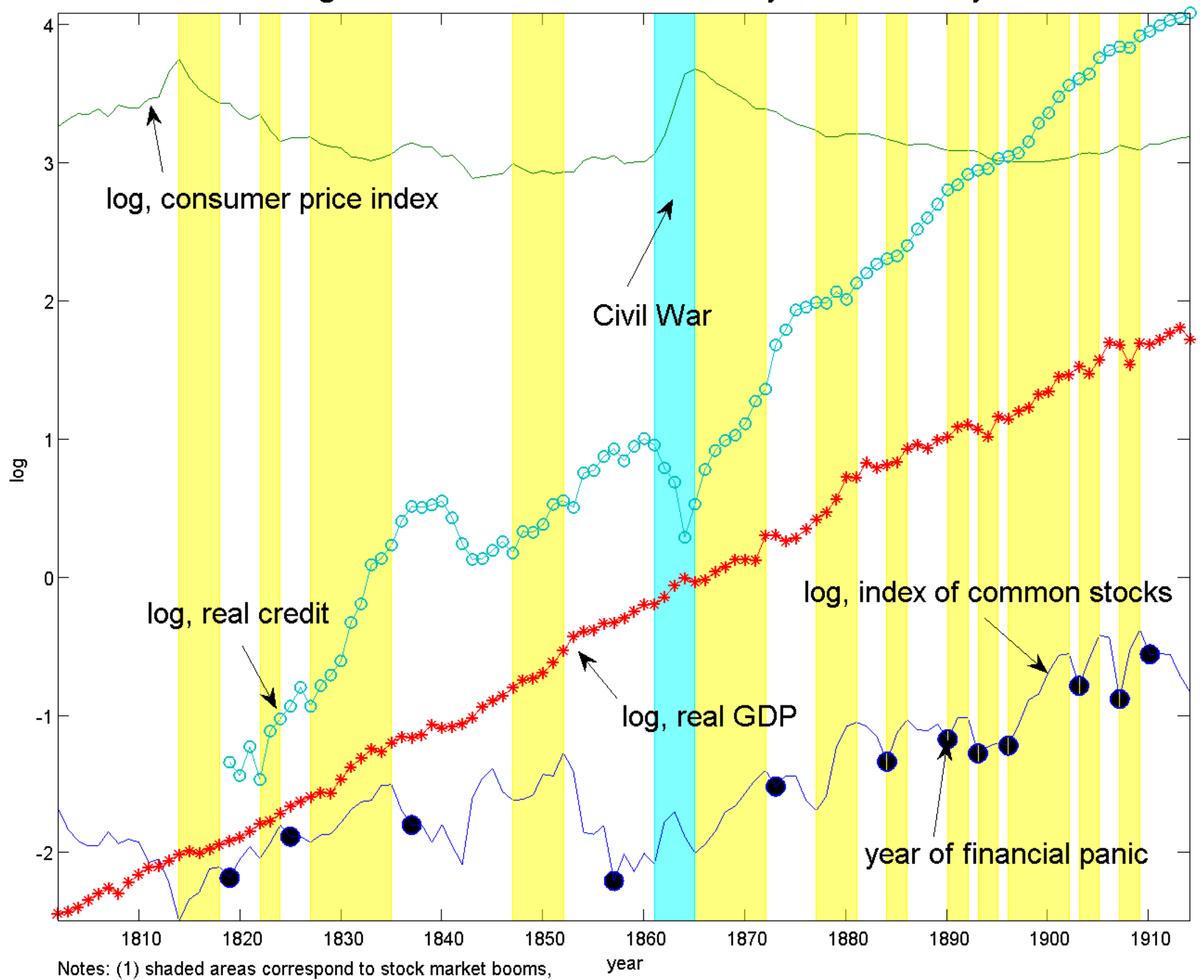

(2) a constant has been added to each variable (after logging), to spread out the time series in the graph and improve visibility.

(3) Civil War is indicated in the figure and excluded from calculations 
Figure 2: Data for 20th and Early 21st Century

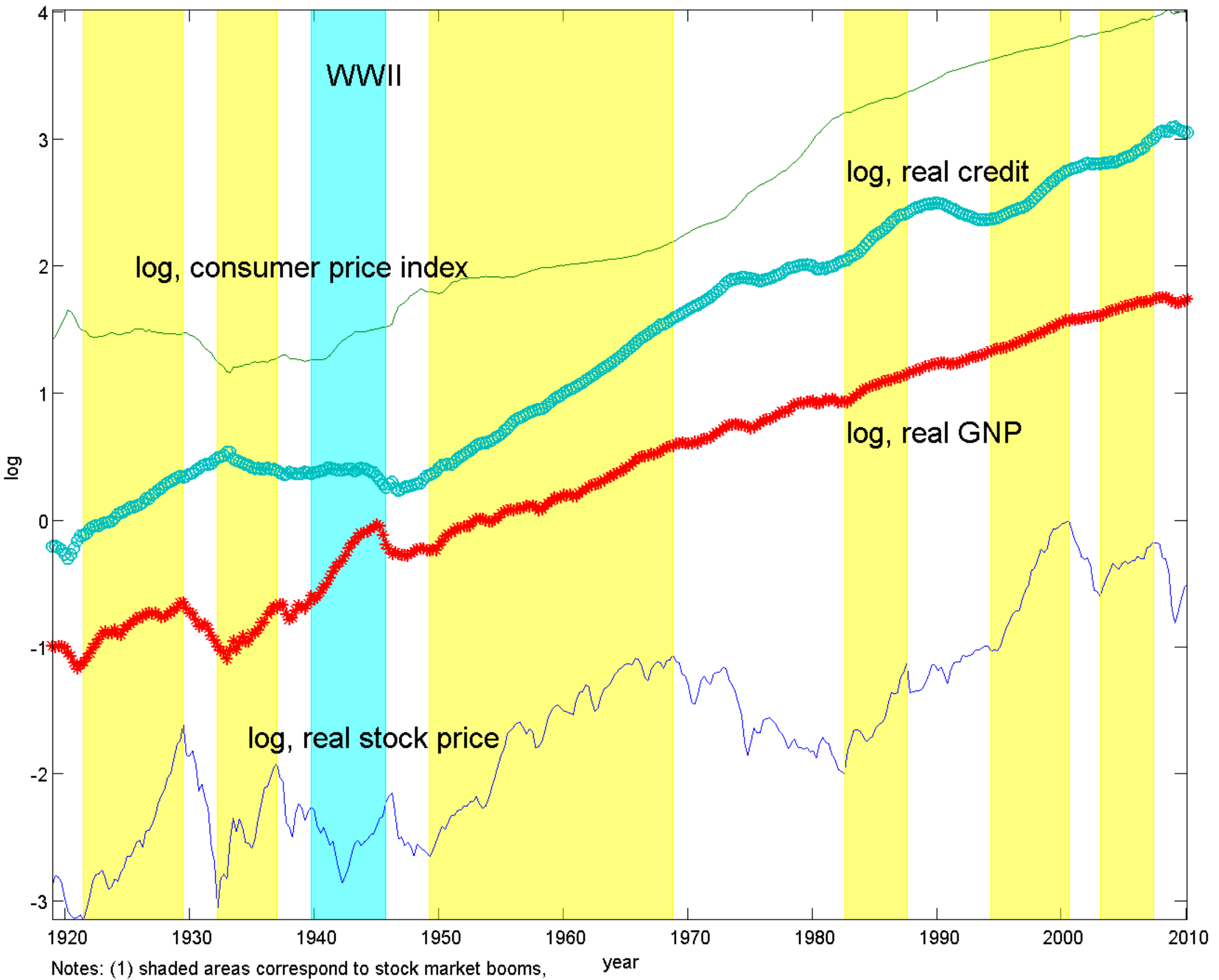

(2) a constant has been added to each variable (after logging), to spread out the time series in the graph and improve visibility.

(3) World War II is indicated in the figure and excluded from calculations 
Figure 3: Japanese Stock Market Boom in 1980s

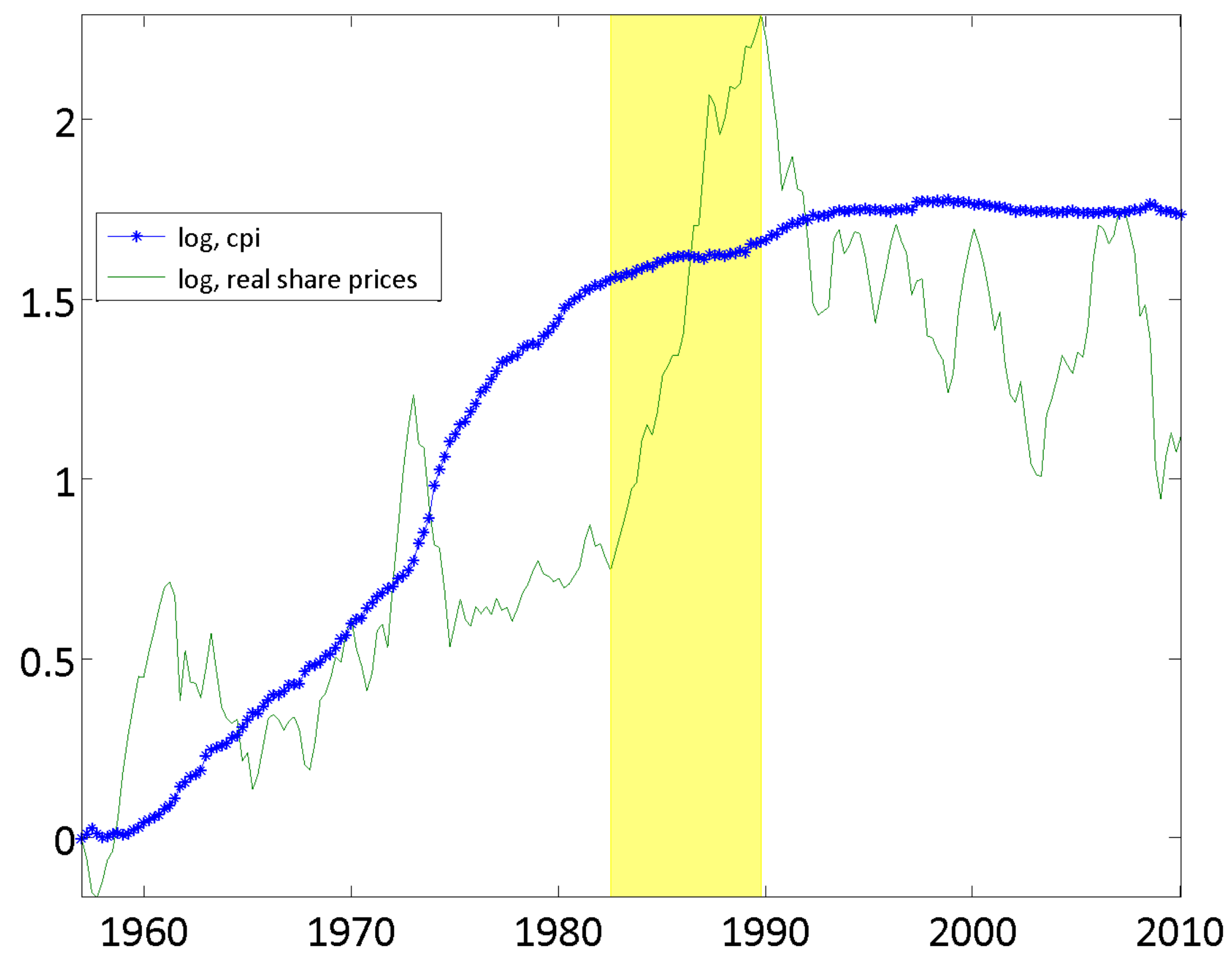


Figure 4: Japan, Actual Rate and Rate Implied by Simple Interest Rate Rule

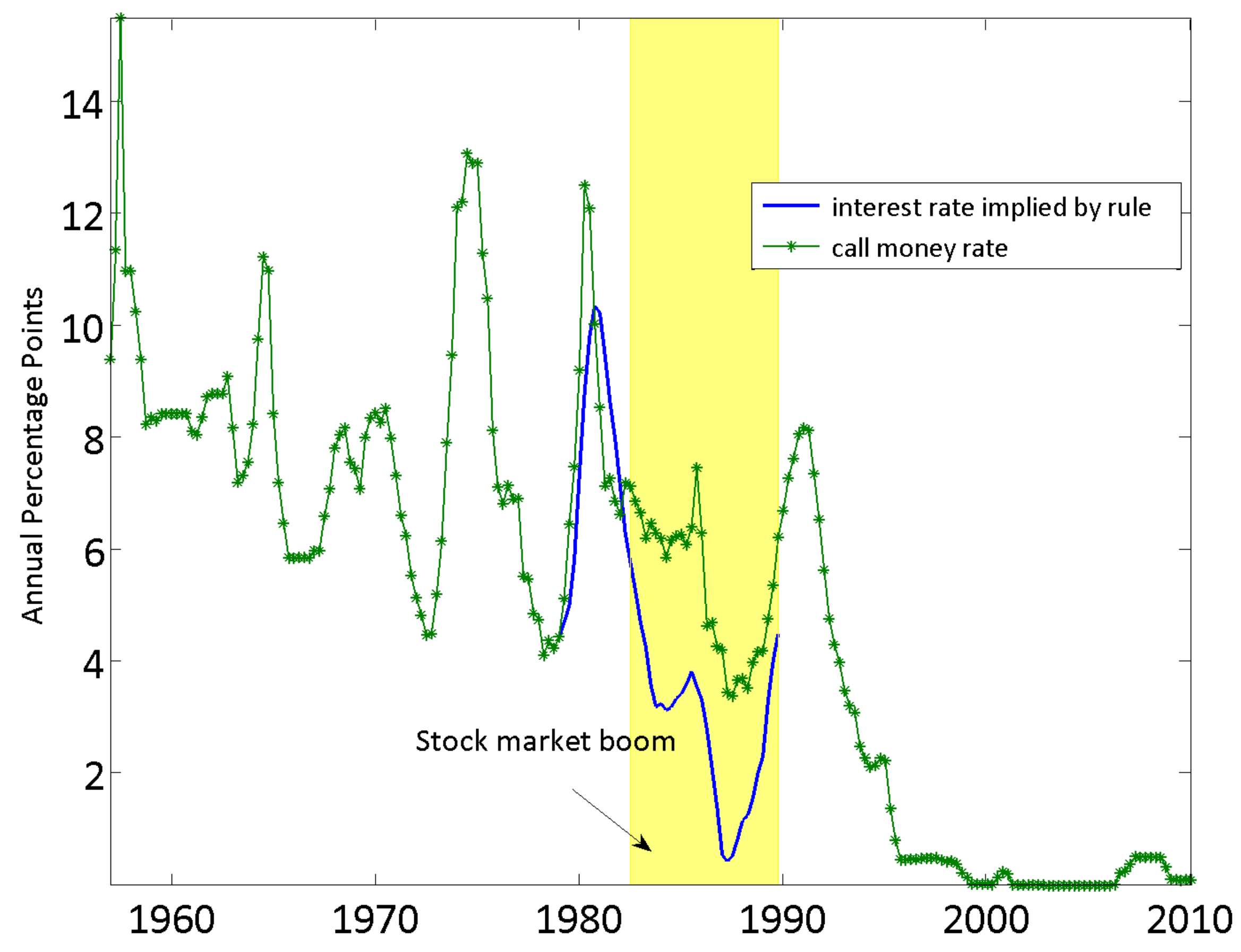


Figure 5: Contemporaneous Effects on Output Gap $\left(\phi_{x}\right)$ and Inflation $\left(\phi_{\pi}\right)$ of a One Percent Signal Shock

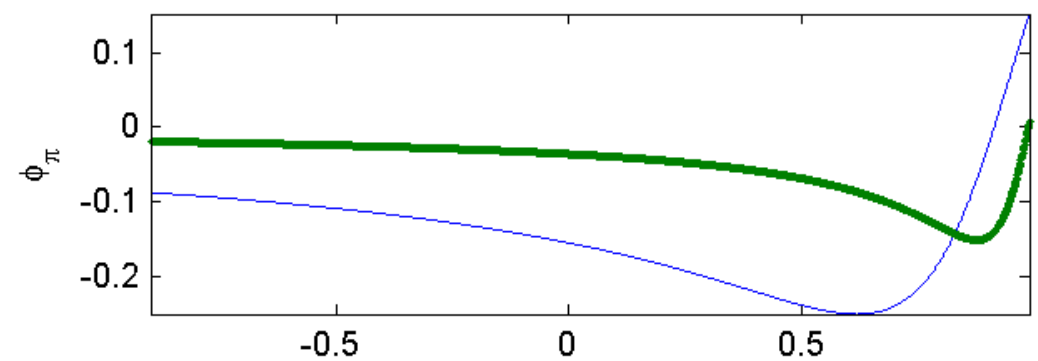

$\rho$, persistence of technology shock

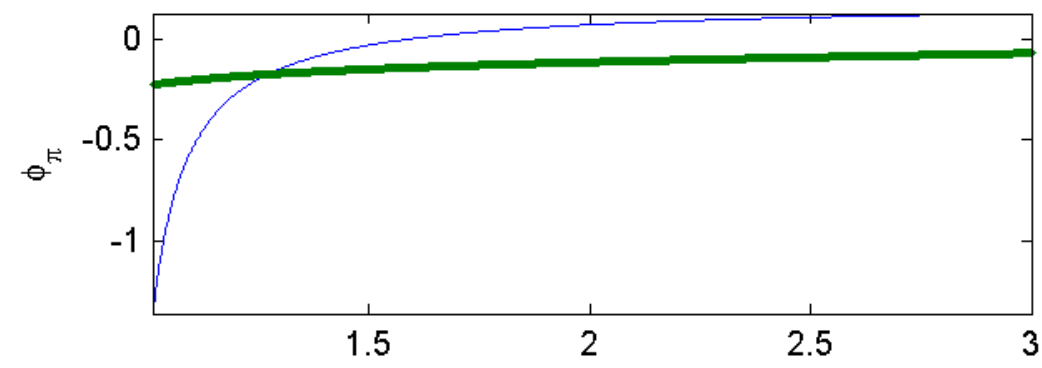

$\mathrm{a}_{\pi}$, monetary policy rule parameter

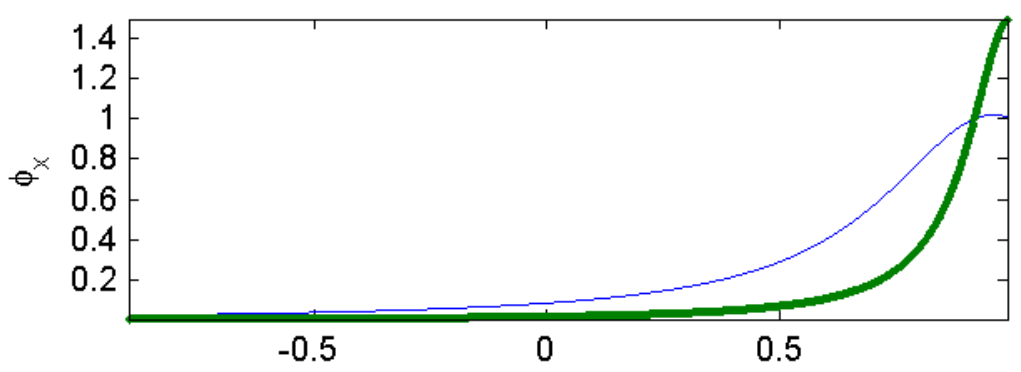

$\rho$, persistence of technology shock

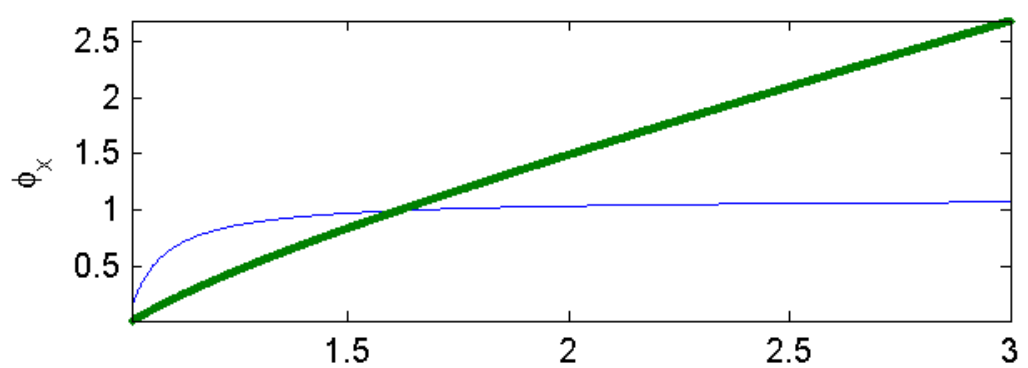

$\mathrm{a}_{\pi}$, monetary policy rule parameter
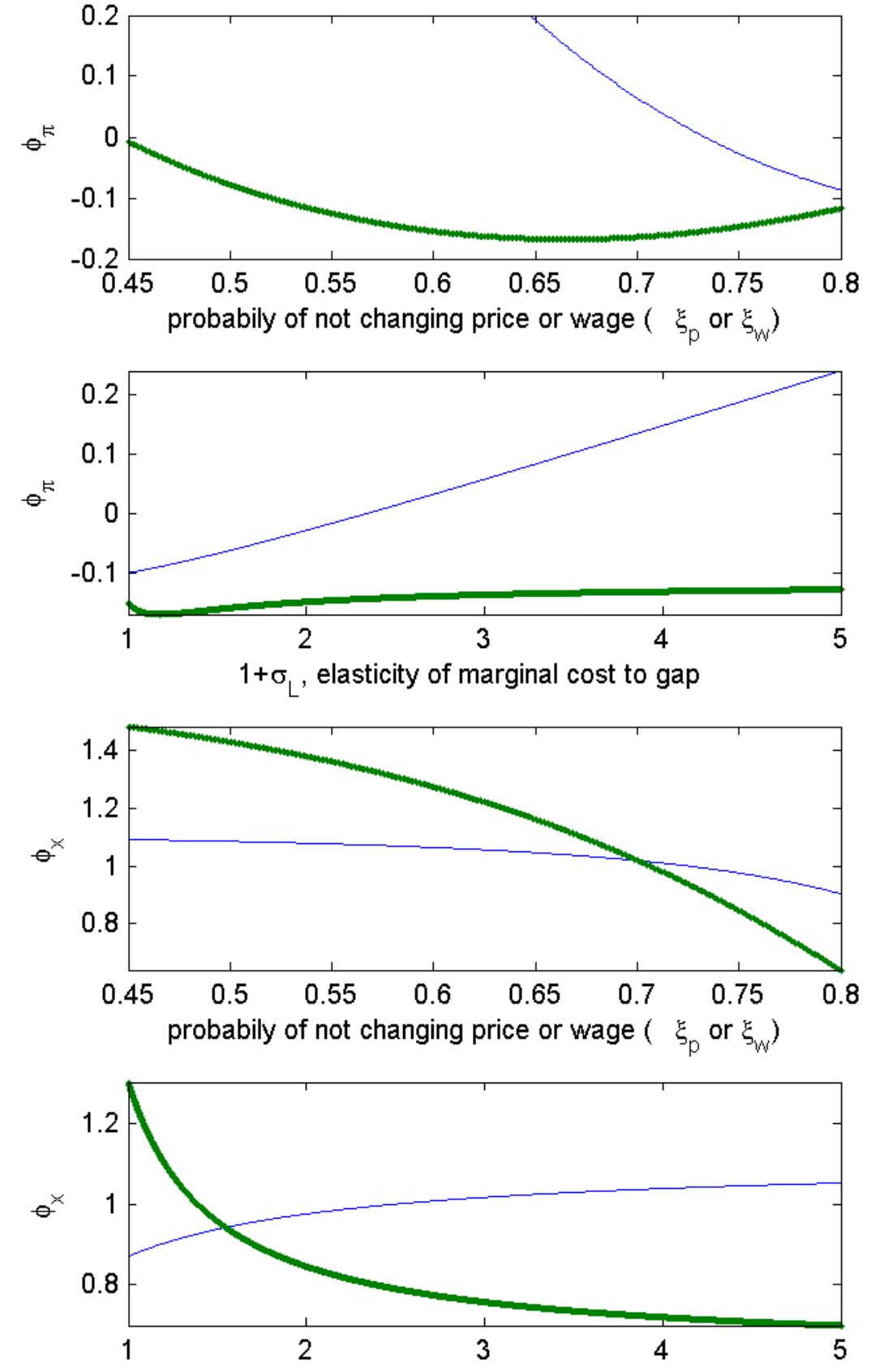

sticky prices sticky wages 
Figure 6: Response of Baseline and Perturbed Model to Signal Shock (Signal not realized); Perturbation = Ramsey
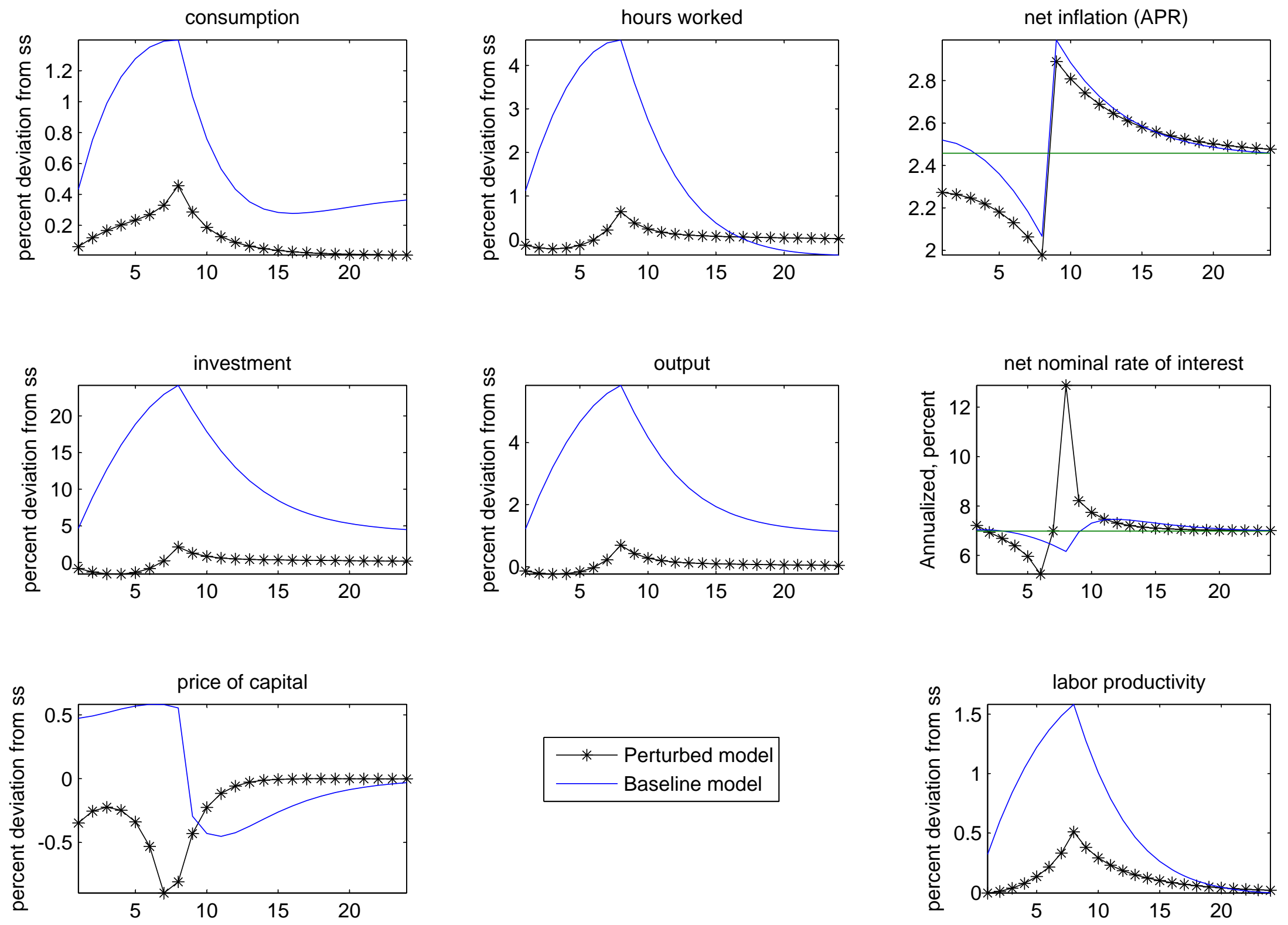


\begin{tabular}{|c|c|c|c|c|}
\hline \multicolumn{5}{|c|}{ Table 1: Variables Over Various Sub-periods, 1803-1914 } \\
\hline Periods & CPI & Credit & GDP & Stock Price \\
\hline Boom & -2.5 & 9.5 & 4.6 & 10.2 \\
\hline Other & 0.7 & 4.0 & 3.1 & -6.3 \\
\hline Non-civil war & -0.7 & 6.5 & 3.7 & 0.8 \\
\hline
\end{tabular}

Notes: (1) numbers represent 100 times average of log first difference of indicated variable over indicated period.(2) Boom periods are the union of the trough to peak periods enumerated in Table $\mathrm{xx} .(3)$ Other are periods that are not booms and that fall outside of 1861-1865. (4) results for credit data based on period, 1819-1914, due to data availability

\begin{tabular}{|c|c|c|c|c|c|}
\hline \multicolumn{7}{|c|}{ Table 2: Variables in Stock Market Boom Episodes } \\
\hline \multicolumn{7}{|c|}{ A. Non-boom, non-civil war, 1803-1914 } \\
\hline \multicolumn{7}{|c|}{ B. Boom episodes } \\
\hline \multicolumn{7}{|c|}{0.7} & 4.0 & 3.1 & -6.3 \\
\hline panic & trough-peak & CPI & Credit & GDP & Stock Price \\
\hline 1819 & $1814-1818$ & -8.0 & na & 1.8 & 9.8 \\
\hline 1825 & $1822-1824$ & -9.8 & 21.9 & 3.7 & 12.1 \\
\hline 1837 & $1827-1835$ & -1.5 & 14.6 & 4.9 & 5.2 \\
\hline 1857 & $1847-1852$ & -1.3 & 7.6 & 5.4 & 6.9 \\
\hline 1873 & $1865-1872$ & -4.1 & 11.9 & 4.8 & 8.5 \\
\hline 1884 & $1877-1881$ & -0.6 & 3.5 & 7.5 & 16.0 \\
\hline 1890 & $1884-1886$ & -2.2 & 4.9 & 5.9 & 15.2 \\
\hline 1893 & $1890-1892$ & 0.0 & 5.6 & 4.5 & 7.9 \\
\hline 1896 & $1893-1895$ & -3.3 & 4.2 & 4.4 & 3.9 \\
\hline 1903 & $1896-1902$ & 0.3 & 8.6 & 5.3 & 11.1 \\
\hline 1907 & $1903-1905$ & 0.0 & 7.6 & 2.3 & 18.3 \\
\hline 1910 & $1907-1909$ & -1.8 & 4.0 & 0.6 & 25.1 \\
\hline
\end{tabular}

Notes: (1) numbers represent 100 times average of log first difference of indicated variable over indicated period. (2) panel A: data averaged over period 1802-1914, skipping 18611865 years and trough to peak years. (3) panel B: data averaged only over the indicated trough-peak years. (4) Panics occur after stock market peak. (5) na signifies 'not available',

observations on credit begin in 1819 


\begin{tabular}{|c|c|c|c|c|}
\hline \multicolumn{5}{|c|}{ Table 3: Variables Over Various Sub-periods, 1919Q1-2010Q1 } \\
\hline Periods & CPI & Credit & GNP & Stock Price \\
\hline Boom & 1.8 & 5.3 & 4.6 & 13.8 \\
\hline Other & 4.0 & 2.3 & 0.2 & -11.7 \\
\hline Whole period & 2.7 & 4.0 & 2.7 & 2.7 \\
\hline
\end{tabular}

Notes: (1) numbers represent 100 times average of log first difference of indicated variable over indicated period.(2) Boom periods are the union of the trough to peak periods enumerated in Table xx.(3) 'Other' are periods that are not booms and that exclude World War II (1939Q4-1945Q4). 'Whole period' corresponds to the full sample, excluding World War II.

\begin{tabular}{|c|c|c|c|c|}
\hline \multicolumn{5}{|c|}{$\begin{array}{l}\text { Table 4: Variables in Stock Market Boom Episodes } \\
\text { A. Non-boom, non-World War II, 1919Q1-2010Q1 }\end{array}$} \\
\hline & CPI & Credit & GNP & Stock Price \\
\hline & 4.0 & 2.3 & 0.2 & -11.7 \\
\hline \multicolumn{5}{|c|}{ B. Boom episodes } \\
\hline trough-peak & CPI & Credit & GNP & Stock Price \\
\hline 1921Q3-1929Q3 & -0.2 & 5.7 & 5.9 & 19.3 \\
\hline 1932Q2-1937Q2 & 0.6 & -2.1 & 6.5 & 24.2 \\
\hline 1949Q2-1968Q2 & 2.0 & 6.3 & 4.2 & 8.1 \\
\hline 1982Q3-1987Q3 & 3.2 & 7.5 & 4.3 & 17.5 \\
\hline 1994Q2-2000Q2 & 2.5 & 6.1 & 3.9 & 16.4 \\
\hline 2003Q1-2007Q1 & 3.0 & 4.6 & 3.0 & 10.1 \\
\hline
\end{tabular}

Notes: (1) numbers represent 100 times average of log first difference of indicated variable over indicated period. (2) panel A: data averaged over period 1919Q1-2010Q1, skipping 1939Q4-1945Q4 and trough to peak years. (3) panel B: data averaged only over the indicated trough-peak years. (4) Panics occur after stock market peak. 
Table 5: Period $t$ Response to News, $\xi_{t}^{1}$, that Period $t+1$ Technology Innovation Will be $1 \%$ Higher

\begin{tabular}{|c|c|c|c|c|c|c|c|c|}
\hline & \multicolumn{8}{|c|}{ In all cases, the natural rate, $R_{t}^{*}$, jumps 100 basis points } \\
\hline & \multicolumn{8}{c|}{$a_{t}=(0.9+\lambda) a_{t-1}-0.9 \lambda a_{t-2}+\xi_{t}^{0}+\xi_{t-1}^{1}$} \\
\hline & \multicolumn{8}{|c|}{ Panel A: Policy rule - $\hat{R}_{t}=a_{\pi} E_{t} \hat{\pi}_{t+1}$} \\
\hline$\lambda$ & \multicolumn{2}{|c|}{$\pi_{t}$} & \multicolumn{2}{c|}{$h_{t}$} & \multicolumn{3}{c|}{$E_{t} R_{t} / \pi_{t+1}$} \\
\hline & Sticky $P$ & Sticky $W$ & Sticky $P$ & Sticky $W$ & Sticky $P$ & Sticky $W$ & Sticky $P$ & Sticky $W$ \\
\hline 0 & -2.8 & -15 & 0.98 & 0.84 & -29 & -175 & -9.8 & -58 \\
\hline 0.125 & -0.42 & -16 & 1.1 & 0.98 & -29 & -178 & -9.8 & -59 \\
\hline 0.2 & 1.7 & -18 & 1.2 & 1.1 & -29 & -181 & -9.6 & -60 \\
\hline 0.6 & 42 & -28 & 2.1 & 2.3 & 8.2 & -200 & 2.8 & -67 \\
\hline 0.8 & 117 & -25 & 2.5 & 4.7 & 111 & -206 & 37 & -69 \\
\hline & \multicolumn{8}{|c|}{ Panel B: Policy rule - $\hat{R}_{t}=a_{\pi} \hat{\pi}_{t}$} \\
\hline 0 & -1.7 & -10 & 0.78 & 0.93 & -2.5 & -15 & 13 & 97 \\
\hline 0.125 & -0.25 & -11 & 0.87 & 1.1 & -0.4 & -16 & 15 & 97 \\
\hline 0.2 & 1.0 & -12 & 0.93 & 1.2 & 1.5 & -17 & 16 & 97 \\
\hline 0.6 & 22 & -16 & 1.4 & 2.3 & 33 & -24 & 35 & 98 \\
\hline 0.8 & 61 & -8.7 & 1.6 & 4.2 & 92 & -13 & 58 & 106 \\
\hline
\end{tabular}

Notes: (1) inflation and rates of return, $\pi_{t}, R_{t}, E_{t} R_{t} / \pi_{t+1}$ expressed in deviations, in units of quarterly basis points, from steady state; (2) hours worked, $h_{t}$, is expressed in percent deviation from steady state; (3) for parameter values, see text. 